\title{
O comportamento no processo de busca da informação por meio das tecnologias da informação e comunicação: um estudo de caso sobre os discentes da Faculdade de Biblioteconomia no Estado do Pará
}

Elisângela Silva da Costa

Mestranda em Educação pelo Programa de PósGraduação em Educação da Universidade Federal do Pará (PPGED/UFPA). Bacharela em Biblioteconomia pela Universidade Federal do Pará (UFPA), Especialista em Gestão da Informação em Bibliotecas Digitais pela UFPA. Bibliotecária Documentalista da Universidade Federal do Pará.

Erik André de Nazaré Pires

Especializando em Ciência da Informação pela Faculdade Integrada Carajás/Centro de PósGraduação Bacharel em Biblioteconomia pela Universidade Federal do Pará (UFPA). Bibliotecário-Documentalista da Universidade Federal do Pará (Campus Universitário de Ananindeua).

http://dx.doi.org/10.1590/1981-5344/1896

Aborda as relações entre o comportamento durante $o$ procedimento de busca informacional e as Tecnologias de Informação e Comunicação (TIC's), tratadas numa perspectiva interdisciplinar no contexto da graduação em Biblioteconomia na Universidade Federal do Pará (UFPA). Objetiva-se investigar como os alunos da graduação em Biblioteconomia realizam as suas pesquisas acadêmicas, averiguando se há êxito nos resultados obtidos, focalizando, em especial, o acesso a textos acadêmicos, para a leitura e produção textual desses discentes, que se encontram em processo de formação profissional. A metodologia foi empregada da seguinte maneira: na primeira com a pesquisa bibliográfica, fundamentada em autores como Kuhlthau (1991; 1999; 2004 e 2005), Wilson (1997; 1999; 2000 e 2006) e abrangendo contribuições de outros pensadores sobre a temática 
abordada. Na segunda etapa, realizou-se um estudo exploratório e descritivo de abordagem quali-quantitativa, com aplicação de questionário contendo perguntas fechadas, abertas e híbridas. Os resultados alcançados mostram que os discentes de modo geral apresentam desempenho satisfatório no processo de busca informacional, pois, realizam o processo de recuperação da informação de modo proficiente.

Palavras-chave: Busca da informação; Tecnologias da Informação e Comunicação; Estudantes de Biblioteconomia; Fontes de Informação; Leitura.

\section{The Behaviour in the process of search of information through information technology and communication: a case study on the students of the School of Librarianship in the State of Pará}

It approaches the relationship between the behavior during the process of information seeking and Information Technology and Communication (ICT), treated in an interdisciplinary perspective in the context of undergraduate Librarianship at the Federal University of Pará ( UFPA ). This study aims to investigate how undergraduate students in Library hold their academic research by examining whether there is successful the results, focusing, in particular, access to academic texts , for reading and textual production of these students, who are in process vocational training. The methodology was as follows: the first with the literature, based on authors such as Kuhlthau $(1991,1999,2004$ and 2005 ), Wilson (1997, 1999, 2000 and 2006) and covering contributions of other thinkers on the subject addressed. In the second step, we performed an exploratory and descriptive study of qualitative and quantitative approach with a questionnaire containing closed, open and hybrid questions. The results show that students generally have satisfactory performance in the information seeking process, therefore, perform the process of information retrieval in a proficient manner. 
Keywords: Information search; Information and Comunication Technologies; Library Science graduation students; Information Sources. Reading.

\section{Introdução}

O advento das Tecnologias de Informação e Comunicação (TIC's) - que tem a internet como um dos seus maiores expoentes - tem potencializado o acesso a conteúdos de diferentes naturezas, inclusive os de caráter técnico e científico, que alimentam 0 processo ensino/aprendizagem nas universidades, o que se reflete diretamente no comportamento na busca de informações por meio desses recursos tecnológicos.

Ao se pensar na Grande Rede Mundial de Computadores, verifica-se que a mesma oferece uma diversidade de fontes de informação nas mais variadas áreas do conhecimento humano, propiciando o contato de alunos e de professores com uma produção teórica que alimenta a produção de outras informações, quer na forma de textos escritos, orais ou audiovisuais.

Neste contexto de proliferação de novas ferramentas facilitadoras do acesso e da produção do conhecimento, atrelado ao comportamento na busca da informação este Trabalho de Conclusão de Curso (TCC) tem como objetivo geral investigar como os alunos da graduação em Biblioteconomia realizam as suas pesquisas acadêmicas, averiguando se há êxito nos resultados obtidos, focalizando, em especial, o acesso a textos acadêmicos, para a leitura e produção textual desses discentes, que se encontram em processo de formação profissional.

A pesquisa buscou traçar o perfil do comportamento dos discentes de Biblioteconomia no uso de tais ferramentas tecnológicas para a recuperação da informação e verificar o hábito de leitura acadêmica por parte dos discentes e no seu ínterim, traçar o perfil pertinente ao comportamento dos discentes de Biblioteconomia no uso de tais ferramentas tecnológicas, para a recuperação da informação

$O$ interesse pela pesquisa surgiu a partir dos seguintes questionamentos: 1) Será que os alunos de Biblioteconomia estão sabendo recuperar adequadamente as informações no seu ambiente acadêmico? e, 2) Será que os discentes de Biblioteconomia estão adotando o comportamento adequado para angariar esse conhecimento necessário?.

O comportamento informacional com um procedimento de obtenção da informação atrelado às TIC's bem concatenado tende facilitar a recuperação da mesma, ocorrendo de uma maneira mais acessível e rápida. Consequentemente essa prática torna-se mais difundida e utilizada, minorando os problemas enfrentados nesse procedimento pela utilização de recursos tecnológicos para esse fim. Neste cerne emergem, questões como: Quais são as barreiras encontradas na utilização das Tecnologias da Informação e Comunicação? 
Tratando-se da questão atinente ao comportamento informacional, questiona-se: Como os discentes de Biblioteconomia estão se comportando no que diz respeito aos sentimentos dos estudantes durante a prática das pesquisas acadêmicas?

Assim, o elemento comportamental, no que diz respeito à recuperação da informação no século XXI é de vital importância para o desenvolvimento da profissão no ramo tecnológico, haja vista a existência de um nicho de mercado de trabalho considerável nesse segmento voltado para a tecnologia. Isso torna o bibliotecário um profissional mais dinâmico, atualizado e melhor preparado, resultando em uma melhor qualificação profissional para desenvolver produtos e serviços mais satisfatórios para os usuários.

Quanto ao referencial teórico, o trabalho apresenta fundamentos de Kuhlthau (1991; 1999; 2004 e 2005), Castells (1999; 2002), Wilson (1997; 1999; 2000 e 2006), Crespo (2005), Immig (2007), Crespo e Caregnato (2003: 2006), Furnival e Abe (2008), sem dispensar as ideias de outros autores que apresentam trabalhos concentrados nesta área de estudo, com o propósito de embasar as bases teóricas que pudessem ajudar na produção do corpo textual e conceituações e análises das informações levantadas.

Quanto a divisão, está segmentado em outro dois tópico, no segundo temo a descrição do percurso metodológico adotado, no terceiro apresentamos o comportamento informacional retratado em seu aspecto histórico, o qual se configura como temática muito estudada na Ciência da Informação em escala global, no quarto tópico são apresentados os resultados e análises dos resultados obtidos com a pesquisa e no útlimo temos as referências utilizadas para subsidiar o desenvolvimento do trabalho científico.

\section{Procedimentos Metodológicos e Operacionais}

Do ponto de vista da caracterização e percurso metodológico, quanto ao objeto de estudo, a pesquisa se caracteriza como bibliográfica, tido como primeiro passo na condução da pesquisa científica que abrangeu a leitura, análise e interpretação de livros, artigos de periódicos, dentre outros materiais informativos sobre a temática abordada. Conforme Lakatos e Marconi (2005, p. 183) a pesquisa bibliográfica: "abrange toda bibliografia já tornada pública em relação ao tema de estudo, desde publicações avulsas, boletins, jornais, revistas, livros, pesquisas, monografias, teses, material cartográfico etc."

Quanto ao objetivo, o estudo consiste de uma abordagem exploratória devido "ter o objetivo de reunir dados, informações, padrões, ideias ou hipóteses sobre um problema ou questão de pesquisa com pouco ou nenhum estudo anterior" (BRAGA, 2007, p. 25). 
Conforme Lakatos e Marconi (2005, p. 190), os estudos exploratórios são aplicados a:

[...] investigações de pesquisa empírica cujo objetivo é a formulação de questões ou de um problema, com tripla finalidade: desenvolver hipóteses, aumentar a familiaridade do pesquisador com um ambiente, fato ou fenômeno, para a realização de uma pesquisa futura mais precisa ou modificar e clarificar conceitos. Empregam-se geralmente procedimentos sistemáticos ou para a obtenção de observações empíricas ou para as análises de dados ou ambas, simultaneamente [...].

Esse tipo de pesquisa tem como foco essencial "proporcionar maior familiaridade com o problema, com vistas a torná-lo mais explícito ou a constituir hipóteses. Pode-se dizer que estas pesquisas têm por objetivo principal o aprimoramento de ideias ou a descobertas de intuições" (GIL, 2009, p. 41).

Ainda compreendendo os objetivos, trata-se também de uma pesquisa descritiva portanto:

Visa descrever as características de determinada população ou fenômeno ou o estabelecimento de relações entre variáveis. Envolve o uso de técnicas padronizadas de coleta de dados: questionário e observação sistemática. Assume, em geral, a forma de Levantamento (GIL, 1991 apud SILVA, E.; MENEZES, 2001, p. 21).

A forma de abordagem compreende a pesquisa quantitativa por buscar: "[...] quantificar opiniões, dados, nas formas de coleta de informações, assim como também com o emprego de recursos e técnicas estatísticas [...]" (OLIVEIRA, S., 2001, p. 115) e qualitativa, porquanto "[...] preocupa-se em analisar e interpretar aspectos mais profundos, descrevendo o comportamento humano. Fornece uma análise mais detalhada sobre as investigações, hábitos, atitudes, tendências de comportamento etc" (LAKATOS; MARCONI, 2009, p. 48).

Também é configurado como um estudo caso, pois tem como parâmetro um estudo aprofundado e exaustivo sobre aspectos característicos permitindo um conhecimento amplo e detalhado de um ou poucos objetos apresentando metodologias flexíveis, no qual, requer equilíbrio intelectual, capacidade de observação, e ainda moderação para não generalizar os resultados (GIL, 2009) e conforme como afirma Yin (2001, p. 32): "[...] um estudo de caso é uma investigação empírica que investiga um fenômeno contemporâneo dentro de seu contexto da vida real, especialmente quando os limites entre o fenômeno e o contexto não estão claramente definidos". Por termos indicativos, o estudo de caso se configura mais apropriado para o desenvolvimento da pesquisa segundo o 
que propõe o ISP de Kuhlthau (1991) e a representação do comportamento informacional de Wilson (1999).

Destarte, em seguida os dados foram coletados com o auxílio de um questionário que de acordo com Lakatos e Marconi (2009, p. 86) trata-se de um "instrumento de coleta de dados constituído por uma série ordenada de perguntas, que devem ser respondidas por escrito e sem a presença do entrevistador [...]" (ver apêndice A) de treze (13) perguntas fechadas, abertas e híbridas, respondidas pelos alunos da Faculdade de Biblioteconomia (FABIB) coletadas durante o período de 01 a 20 de dezembro de 2011 e foi entregue de maneira presencial ao elaborador do mesmo. Optou-se por este instrumento, por servir tanto a abordagem qualitativa quanto quantitativa, além de permitir maior privacidade ao respondente e mostrar-se de aplicação mais simples e rápida, também foi levado em consideração o fato da tabulação e interpretação de dados venha ser mais simplificada.

Para elaborar as questões, procurou-se chegar a perguntas simples e diretas, cuja as respostas pudessem evidenciar os diferentes aspectos do comportamento informacional sugerido por Wilson (1999) e do ISP de Kulhthau (1991).

O estudo tem como propósito retratar o comportamento durante o processo de busca informacional dos discentes da Faculdade de Biblioteconomia da UFPA que é constituído ao todo de uma população de: "trezentos e quatorze alunos (314) alunos, sendo cento e setenta (170) discentes matriculados no turno matutino e cento e quarenta e quatro (144), no turno noturno" (UNIVERSIDADE FEDERAL DO PARÁ, 2011, não paginado), na utilização de fontes digitais, com foco especial nos periódicos cientificos eletrônicos.

Partiu-se de um universo composto de graduandos da Faculdade de Biblioteconomia (FABIB) da UFPA, foi feita uma seleção amostral de caráter não probabilístico de estudantes que se encontravam em níveis: básico, intermediário e avançado de formação, e que já utilizam as TIC's, onde podem ter acesso a textos acadêmicos, como também já se comportam com provável desenvoltura na utilização destes recursos por meio dos quais encontram boa parte das fontes especializadas em Biblioteconomia e em Ciência da Informação

Em termos numéricos foram aplicados cem (100) questionários, distribuídos pessoalmente, o que corresponde a aproximadamente trinta e dois por cento (32\%) do total de alunos, sendo que foram devolvidos de maneira presencial 50 (cinquenta), quantidade esta que vai ser considerada para análise dos dados coletados, o que vem a garantir uma amostra suficiente para desenvolver um estudo com propriedade no que concerne à tabulação dos dados na pesquisa, o que resultou aproximadamente a uma taxa de retorno de dezesseis por cento (16\%).

A escolha das turmas deu-se em função dos alunos estarem cursando em variados períodos de formação acadêmica, que vão desde o básico até o avançado com relação ao quesito aprendizagem, e por se tratar de discentes que conseguem realizar as suas pesquisas acadêmicas 
de maneira, aparentemente consistente, haja vista a imensa gama de informações disponíveis para consulta, principalmente dispostas na web.

Os dados são apresentados em forma de texto, quadro e gráficos, de acordo com as características das perguntas e das respostas obtidas. As questões elaboradas para respostas abertas proporcionaram respostas passíveis de categorização, assim permitindo, da mesma resposta, retirar dados quantitativos e qualitativos.

Por essa forma, a expressão comportamento informacional que da "língua inglesa vem a ser, mais conhecida na literatura estrangeira de Ciência da Informação como information behavior, também é encontrado em idioma espanhol com o termo conducta informacional" (GONZALES TURUEL, 2005 apud IMMIG, 2007, p. 20).

A sua abrangência consta de um campo de pesquisa que surgiu a partir da elaboração de estudos feitos por cientistas, antes mesmo do 2008). aparecimento do termo Ciência da Informação (FURNIVAL; ABE,

\section{Comportamento Informacional}

O comportamento informacional juntamente com o processo de busca e, consequentemente, o uso da informação auferida são temáticas relevantes para pesquisa na área de Biblioteconomia e da Ciência da Informação, por isso é indispensável entender como é feito esse processo de recuperação da informação, tanto o profissional bibliotecário quanto o discente precisam estar aptos a realizar esse procedimento, tanto para angariar conhecimento como para atender à demanda dos usuários no seu ambiente de trabalho, em qualquer unidade de informação que venha a desenvolver suas atividades profissionais. Portanto, um estudo dessa temática abre diferentes possibilidades de percepções de busca, fonte e forma harmoniosa na utilizacão da informacão.

Wilson (1999, p. 250, tradução nossa) apresenta como origem desse campo a I Conferência de Informação Cientifica da Royal Society, realizada em 1948:

[...] ocasião em que muitos estudos sobre comportamento de busca da informação foram apresentados - embora sem 0 emprego do termo comportamento informacional - com reflexões orientadas às necessidades de informação de usuário, principalmente usuários especializados, como cientistas e pesquisadores ${ }^{1}$.

\footnotetext{
${ }^{1}$ Royal Society Scientific Information Conference of 1948 , when a number of papers on the information behaviour of scientists and technologists were presented. Of course, the term information behaviour was not used in the papers, which were generally about document and library use, but the origins are clearly there.
} 
A partir de então, estudos foram realizados ao longo das décadas e delinearam diferentes etapas, que estão distribuídas no quadro 1.

Quadro 1 - Evolução das abordagens sobre o comportamento informacional

\begin{tabular}{|c|c|}
\hline Década & Descrição \\
\hline 1940 & $\begin{array}{l}\text { Os estudos restringiam-se à área de Exatas e objetivavam agilizar e aperfeiçoar os produtos e serviços } \\
\text { oferecidos pelas bibliotecas }\end{array}$ \\
\hline 1950 & $\begin{array}{l}\text { Intensificaram-se os estudos sobre o uso da informação entre grupos específicos de usuários, englobando as } \\
\text { Ciências Aplicadas }\end{array}$ \\
\hline 1960 & $\begin{array}{l}\text { Nessa época, os estudos passam a contemplar questões relativas ao comportamento de usuários, como } \\
\text { tecnólogos e educadores, surgindo estudos de fluxos da informação, canais formais e informais. Data desse } \\
\text { período o crescimento de estudos que analisam os diferentes aspectos de busca e uso da informação, } \\
\text { designando os estudos sobre "Necessidades e Usos da Informação"; }\end{array}$ \\
\hline 1970 & $\begin{array}{l}\text { Neste período, emergem estudos relativos aos usuários e à satisfação de suas necessidades de informação, } \\
\text { caracterizando-se como estudos de necessidades que, por sua vez, passariam a divergir em duas direçôes: } \\
\text { abordagem tradicional (systemoriented approach ou traditional approach), dirigida sob a ótica do sistema de } \\
\text { informação; e abordagem alternativa, dirigida sob a ótica do usuário (user-oriented approach ou alternative } \\
\text { approach. São dessa época estudos sobre usuários das áreas de humanas, ciências sociais e administrativas; }\end{array}$ \\
\hline 1980 & de satisfação e desempenho. \\
\hline
\end{tabular}

Fonte: Furnival e Abe (2008, p. 159)

Wilson (1999) explica que uma das principais críticas feitas na realização desses estudos devia-se ao fato destes não terem tido base em pesquisas prévias, de forma a consolidarem um corpo teórico e de estudos empíricos que poderiam servir como ponto de partida para pesquisas futuras, os estudos eram influenciados por uma tradição positivista centrando métodos de pesquisas quantitativas, o que representaram inapropriados para os estudos do comportamento humano e contabilizavam informações como por exemplo: a quantidade de visitas às bibliotecas, o número de assinaturas pessoais de periódicos e o número de citações nos artigos. Esses números mostraram poucos dados de relevância para o desenvolvimento da teoria ou mesmo da prática do processo de busca e uso da informação.

Não obstante, nas últimas décadas, mais precisamente nos últimos dez a quinze anos esse paradigma vem se modificando, em decorrência da aplicação de métodos de abordagens qualitativas, abundantes principalmente de estudos britânicos, no qual exercem enorme tradição em estudos de comportamento informacional (FURNIVAL; ABE, 2008; WILSON, 1999).

$\mathrm{Na}$ literatura, alguns trabalhos de pesquisadores têm provocado influências decisivas a elaboração de mais estudos de comportamento na área, cabe destacar as abordagens dos pesquisadores norte-americanos Wilson e Kuhlthau que são o foco deste trabalho acadêmico, entretanto, existem mais autores que tratam dessa temática como é o caso de Dervin e Elis (FURNIVAL; ABE, 2008).

Esses estudos estão concernentes à literatura internacional, pois, essa análise procura investigar a busca da informação em vários níveis, como por exemplo: 
Estudos no quais são descritas atividades e tarefas específicas; Estudos que têm identificado aspectos afetivos ou cognitivos de usuários; e

Modelos teóricos e descritivos de busca da informação em sistemas de informação ou comportamento informacional (FURNIVAL; ABE, 2008, p. 160)

Para fins deste estudo, consideramos comportamento informacional o resultado do reconhecimento de alguma necessidade de informação sobre determinado assunto que se queira ter conhecimento, dessa forma, o indivíduo realiza vários procedimentos de busca da informação para suprir essa lacuna (WILSON, 1999). O paralelo entre comportamento e busca informacional não é algo casual, pois, a atividade mais complexa dentro do comportamento informacional seja justamente a busca, por envolver, no mesmo processo diferentes etapas, ou características.

Crespo (2005, p. 31), analisa que o comportamento de busca e uso da informação apresenta-se uma atividade complexa, no qual:

[...] envolve vários aspectos, podendo ser analisada sob muitas formas, as quais podem apresentar alterações devido a fatores, como o direcionamento que cada área do conhecimento dá para suas pesquisas, a atividade que a pessoa exerce, em que etapa da vida profissional se encontra, entre outros. Esses fatores podem fazer com que o indivíduo utilize fontes de informação específicas e adote etapas e procedimentos diferenciados de outros indivíduos. assim:

Há inúmeras causas que envolvem esse comportamento, sendo

O objetivo declarado é caracterizar as mudanças progressivas que acontecem no processo de busca da informação pelos usuários, incluindo: contexto situacional do usuário; problemas do usuário na busca da informação; redução de incerteza; estados cognitivos e afetivos de usuários quanto a sucessivas buscas, e por conseguinte nas suas questões de estilos cognitivos (BEAULIEU, 2003, p. 245, tradução nossa)2.

O uso da informação é outro conceito componente do comportamento informacional, e refere-se à:

[...] à atividade fim que 0 indivíduo pretende exercer com a informação que obteve. Seria uma etapa imediatamente posterior à busca, se considerarmos a busca composta por

\footnotetext{
${ }^{2}$ The stated goal is to characterize the progressive changes that occur in the process of searching for information by users, including: the situational context of the user; problem of user information seeking, uncertainty reduction, cognitive and affective states of users and the subsequent searches, and therefore issues in their cognitive styles.
} 


\section{subetapas de recuperação e avaliação da informação recuperada, precedendo o uso (IMMIG, 2007, p. 14).}

Em se tratando de Brasil estudos sobre essa área são mais escassos, sendo mais frequentes estudos que abordam, de acordo com Furnival e Abe (2008, p. 163):

[...] a necessidade de informação de usuários de redes eletrônicas de universidade e centros de informação especializados. Parece haver uma lacuna deixada por esses estudos, ao não contemplarem o comportamento de busca da informação na internet de usuários comuns; cidadãos comuns que buscam a informação - as mais variadas - para atender as suas necessidades.

Os estudos diante dessa perspectiva podem ser explorados com mais ênfase, pois, vivemos em uma sociedade que depende das tecnologias que foram desenvolvidas para auxiliarem os mais variados tipos de consulentes com propostas de subsidiarem o atendimento da necessidade de obter a informação, abrangendo rapidez e proficiência na recuperação da mesma.

Diante desse cenário Immig (2007, p. 23) comenta que o: "comportamento informacional pode ser considerado uma constante na vida das pessoas, visto que necessidades de informação fazem parte da vivência humana" e contribui decisivamente para o crescimento científico e cultural do ser humano.

Além do comportamento informacional, existem outros dois subcampos que abrangem esse campo, que são os seguintes: comportamento de busca de informação (information seeking behaviour), que por sua vez, abrange o subcampo comportamento de busca em sistema de informação (information searching behaviour), essas definições distribuídas no quadro expresso a seguir.

\section{Quadro 2 - Definições de Wilson a respeito do comportamento} informacional

\begin{tabular}{|c|c|c|}
\hline $\begin{array}{c}\text { Information Behavior } \\
\text { (Comportamento Informacional) }\end{array}$ & $\begin{array}{l}\text { Information Seeking Behavior } \\
\text { (Comportamento de Busca da } \\
\text { Informação) }\end{array}$ & $\begin{array}{l}\text { Information Searchir Continuação } \\
\text { (Comportamento de busca em sıstema de } \\
\text { informação) }\end{array}$ \\
\hline $\begin{array}{l}\text { E a totalidade do comportamento } \\
\text { humano em relação às fontes e } \\
\text { canais de informação, incluindo a } \\
\text { informação ativa e passiva busca } \\
\text { e uso da informação. Assim, inclui } \\
\text { a comunicação face com os outros } \\
\text { meios de comunicação, bem como } \\
\text { a recepção passiva da informação } \\
\text { como, por exemplo, vendo } \\
\text { propagandas de TV, sem qualquer } \\
\text { intenção de agir sobre a } \\
\text { informação dada }{ }^{3} \text {. }\end{array}$ & $\begin{array}{l}\text { É a busca intencional para obter } \\
\text { informações como conseqüência } \\
\text { de uma necessidade de satisfazer } \\
\text { alguma meta. No decorrer da } \\
\text { busca, o indivíduo pode interagir } \\
\text { com sistemas de informação } \\
\text { manuais (como um jornal ou uma } \\
\text { biblioteca), ou com o computador- } \\
\text { sistemas baseados (como a World } \\
\text { Wide Web) }{ }^{4} \text {. }\end{array}$ & $\begin{array}{l}\text { É o "nível-micro" de comportamento empregado } \\
\text { pelo pesquisador na interação com sistemas de } \\
\text { informação de todos os tipos. É composto por } \\
\text { todos os tipos de interações com o sistema, quer } \\
\text { ao nível da interação homem-computador (por } \\
\text { exemplo, o uso do mouse e clique em links) ou em } \\
\text { nível intelectual (por exemplo, adotando uma } \\
\text { estratégia de busca booleana ou determinar os } \\
\text { critérios para decidir qual dos dois livros } \\
\text { selecionados de lugares adjacentes em uma } \\
\text { prateleira de biblioteca é mais útil), que envolverá } \\
\text { também atos mentais, como julgar a relevância de } \\
\text { dados ou informações recuperados. }\end{array}$ \\
\hline
\end{tabular}

Fonte: Wilson (2000, p. 49, tradução nossa) 
Os canais informacionais mencionados pelo autor representam o conjunto formando as tecnologias que congregam a informação e comunicação que os indivíduos utilizam no seu dia a dia (WILSON, 1999).

Para um entendimento melhor a respeito dessa configuração no que compete a esse estudo do ciclo envolvendo a busca da informação, abaixo tem-se uma figura que comporta de maneira clara como está cisão está delineada.

Figura 1 - Modelo das áreas de pesquisa em busca de informação e busca em sistemas de informação

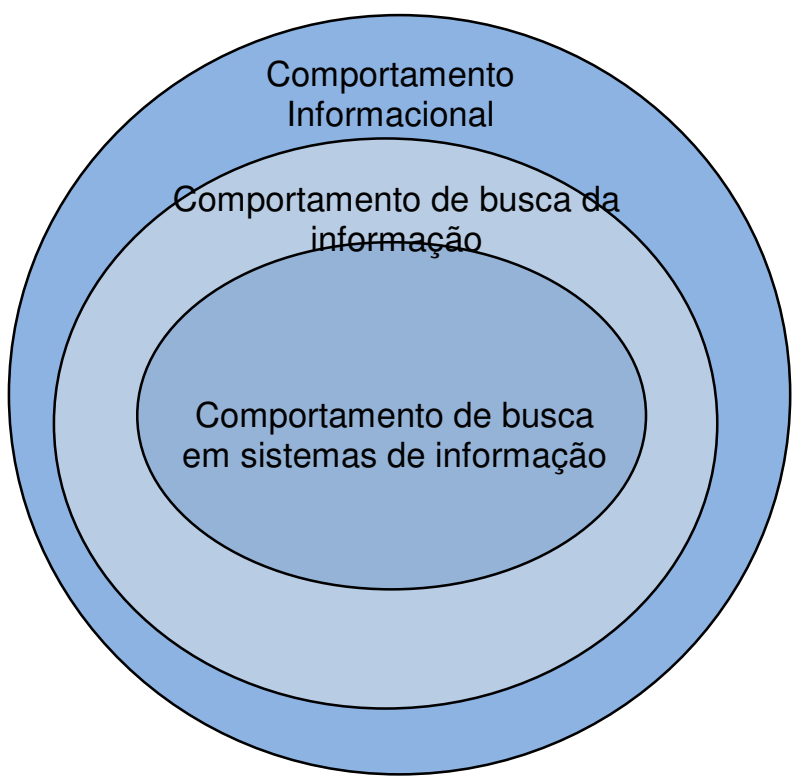

Fonte:Wilson(2000,52,tradução nossa)

A figura 1 sintetiza como ocorre este processo, sendo que o comportamento informacional está no topo dessa hierarquia, já o comportamento de busca da informação e, por conseguinte, o comportamento de busca em sistemas de informação formam dois subconjuntos, que se complementam no intuito de fornecer uma gama de fontes de informações para os consulentes através de um sistema computadorizado.

As três formas, expressas pelo modelo sugerido, segundo o autor são:

a) buscar informação através de um sistema de informação, onde o usuário recorre a "sistemas formais costumeiramente definidos como sistemas de informação"6 (WILSON, 2006, p.660, tradução nossa), por exemplo, uma unidade de informação;

b) buscar informação em "sistemas que podem desempenhar funções informacionais como complemento a uma função 
primária, não informacional"7 (WILSON, 2006, p.660, tradução nossa), por exemplo, uma

repartição pública ou uma empresa;

c) e, "alternativamente, o usuário pode procurar informação de outras pessoas, em detrimento dos sistemas" ${ }^{\prime \prime}$ (WILSON, 2006, p.660, tradução nossa), isto é, buscar informação de uma fonte pessoal.

Em qualquer um dos três níveis de comportamento de busca de informação, apresentados no modelo, pode haver falha ou sucesso. No diagrama estas possibilidades estão indicadas apenas nos sistemas, mas também podem ocorrer quando se procura informação de outras pessoas (WILSON, 2006).

No caso de êxito, isto é, a demanda por informação ser atendida, acontece o 'uso da informação'. Wilson (2006, p.660, tradução nossa) indica que o "[...] 'uso' pode satisfazer ou falhar na satisfação da necessidade e, em outro evento, pode também ser reconhecido como sendo de relevância potencial para necessidade de outra pessoa e, conseqüentemente, pode ser 'transferida' para tal pessoa." ${ }^{\prime 9}$

Com a não-satisfação da necessidade, o processo expresso pelo diagrama a

partir da identificação de uma necessidade de informação vem a repetir. O usuário pode adotar caminhos alternativos à primeira tentativa. Mesmo com a satisfação da necessidade, esta pode criar ou explicitar ao usuário outras necessidades de informação, dando sequência ao comportamento de procura de informação um processo com fluxo constante.

No que diz respeito aos fatores que influenciam a maneira da elaboração da busca informacional, existem dois que são aplicados de forma concisa durante esse processo de recuperação da informação, que são destacados segundo Leckie, Pettigrew e Sylvain (1996 apud MARTINEZ-SILVEIRA; ODDONE, 2007, p. 121, grifo nosso) que são as seguintes:

Fontes de Informação: Locais onde são procuradas às informações. A depender do profissional e das características da informação que se busca, essas fontes variam, variando também a ordem em que as fontes são consultadas. As fontes mais comumente referidas são colegas, bibliotecas, livros, artigos e a própria experiência. Essas fontes assumem diversos formatos e podem ser cessadas por diferentes canais, tanto os formais quanto os informais. Há fontes externas e internas, orais e escritas, pessoais e coletivas. 
Conhecimento da informação: O conhecimento direto ou indireto das fontes, do próprio processo de busca e da informação recuperada desempenham importante papel no sucesso da busca. Algumas variáveis que devem ser consideradas neste sentido são familiaridade ou sucesso em buscas anteriores, confiabilidade e utilidade da informação, apresentação, oportunidade, custo, qualidade e acessibilidade da informação.

Por essa forma, existem oito (8) variáveis que estão inclusos para fazer a intervenção no processo de busca informacional, que são compostos segundo Wilson (1997, p. 552, tradução nossa): "(a) pessoais; (b) emocionais; (c) educacionais; (d) demográficas; (e) sociais ou interpessoais; ( $f$ ) de meio ambiente; ( $g$ ) econômicas; (h) relativas às fontes (acesso, credibilidade, canais de comunicação) ${ }^{\prime 10}$, tais fatores ficam expostos quando o usuário realiza a busca da informação, pois, abarcam as situações que estão a volta de quem está procurando material informativo para supressão da necessidade.

Partindo do fato que o comportamento na busca da informação passa por etapas necessárias a sua efetivação, o mesmo é definido segundo Crespo e Caregnato (2003, p. 249) como: "[...] compreender características complexas da ação e interação nas quais as pessoas se engajam quando procurando por informações de qualquer tipo e para qualquer propósito", proporcionando, assim, muitas dúvidas durante o processo de obtenção da informação.

Para Patrícia Silva (2008, p. 260), existem fatores que comprometem o comportamento do consulente, como "[...] a habilidade técnica específica desse usuário, influenciando diretamente na utilização dos sistemas; assim como o contexto e o espaço onde a pessoa desenvolve o uso", identificando que há uma necessidade de melhor preparação desse usuário no âmbito da recuperação informacional.

\subsection{O procedimento na busca da informação}

Para esse trabalho adotaremos para estudo 0 modelo de comportamento de busca e uso da informação intitulado por Information Search Process (ISP), esse trabalho foi desenvolvido pela pesquisadora norte-americana Carol Collier Kuhlthau ${ }^{11}$ :

[...] que estudou os padrões do processo de busca e uso da informação de estudantes de graduação, durante a realização do seu Trabalho de Conclusão de Curso [no ano de 1991]. A autora definiu um modelo centrado no indivíduo, levando em consideração os sentimentos, pensamentos e ações que ocorrem durante o processo (CRESPO, 2005, p. 31). 
A sua caracterização se dá pela: "[...] atividade de pesquisa em estágios conhecidos como: iniciação, seleção, exploração, formulação, coleção e apresentação"12 (KUHLTHAU, 2004, p, 52, tradução nossa), seguindo nessa linha de raciocínio em termos de pesquisa, Fialho (2010, p. 167) diz que: "[...] nessa perspectiva alguns estágios são mais difíceis para os estudantes do que outros".

Todavia, esses estágios estão ligados aos processos cognitivos e afetivos dos usuários e nos estágios iniciais de processo de busca de informação segundo Kuhlthau (2004, p. 6, tradução nossa):

[...] a especificação precisa da necessidade pode ser impossível para o usuário, sendo que à medida que ele tem maior compreensão de seu problema pode ocorrer uma alteração em sua habilidade de representar sua necessidade para o sistema de informação ${ }^{13}$.

Desse modo, acarretando mais tempo para o consulente poder fazer sua pesquisa de maneira correta e consequentemente, mais frustração no que compete à recuperação da informação de forma proficiente.

O ISP conforme Kuhlthau (1991, p. 366, tradução nossa), é visto como:

[...] uma atividade realizada pelo indivíduo para dar sentido a uma informação e para ampliar seu estado de conhecimento sobre um problema ou tópico específico. A incerteza diante da falta de compreensão, de um vazio de significado, de uma construção limitada com relação a algum assunto ou situação problemática, dá início ao processo ${ }^{14}$.

As questões do ISP estão associadas à complexidade perante a construção de uma busca mais completa para obtenção informacional e ainda não foi formalmente estudado no contexto do profissional da informação, o processo na recuperação da informação abriga complexas tarefas que vai além da diminuição da incerteza, na qual esta mesma é associada com tarefas mais complexas e pode aumentar com o recebimento de mais informações (KUHLTHAU, 1999).

Kuhlthau (2004, slide 4, tradução nossa) explana com propriedade acerca desse procedimento que abriga a incerteza quando se faz uma busca que vai suprir a necessidade informacional:

Os sintomas afetivos de incerteza, confusão e frustração estão associados a pensamentos vagos e pouco claros sobre um tópico ou pergunta. Como os estados de conhecimento tendem a mudar com pensamentos mais claramente focados, uma mudança paralela ocorre e sentimentos de confiança aumentam. Incerteza devido a uma falta de compreensão, uma lacuna de significado, ou uma construção limitada inicia o processo de busca por informação ${ }^{15}$. 
Partindo dessa abordagem, Kuhlthau (2004, slide 7, tradução nossa) apresenta em seu estudo, critérios para escolha do ISP, no qual estão apresentados a seguir "Tarefa - O que estou tentando realizar? - Tempo Quanto tempo eu tenho? - Interesse - O que eu acho pessoalmente interessante? - Disponibilidade - Qual informação está disponível para mim? ${ }^{\prime \prime 16}$, esses questionamentos são valiosos para fazer um uso exitoso desse procedimento.

Continuando apresentar certa linearidade, constituindo da forma como é descrito o ISP, Venâncio e Nassif (2008, p. 98) apresentam que na sua conjectura que esse processo se constitui em:

[...] recursivo e interativo e raramente se desenvolve diretamente da fase de seleção para a apresentação. Tome-se, como exemplo, o estágio da formulação do foco, o qual representa o ponto crítico do processo de busca da informação e serve como orientador e selecionador de inúmeras opções, especialmente em condições de muita incerteza, ambigüidade e sobrecarga informacional. Essa etapa, após sua finalização, quando o foco é bem estabelecido, tende a propiciar certa estabilidade emocional, uma vez que a incerteza e a confusão decrescem, a confiança aumenta e o interesse se intensifica. Não obstante, é justamente nessa fase que usualmente se identificam sentimentos de ansiedade, insegurança e confusão, típicos do início da busca, quando se seleciona e explora grande quantidade de informações.

$\mathrm{Na}$ sua atuação como papel fundamental na recuperação da informação esse mecanismo de busca de informações "[...] é um processo de construção que envolve toda a experiência da pessoa, sentimentos, bem como pensamentos e ações"17 (KUHLTHAU, 1991, p. 362, tradução nossa). Choo (2003, p. 103) considera que esse processo "faz parte de uma atividade social por meio da qual a informação torna-se útil para um indivíduo ou para um grupo", compondo-se de aspectos que abrigam no ser humano o seu dia a dia, e as tecnologias da informação representam um papel importante nessa técnica de recuperabilidade informacional (ORTOLLESPINET; GONZÁLEZ-TERUEL; GIALABERT-ROS, 2009), sendo empregadas constantemente como facilitadores no aspecto de atualização perante o mercado de trabalho.

Para Kuhlthau (2005), a obtenção de informação se faz através de um processo de busca por significado e não se limita apenas a satisfazer demandas, ou seja, encontrar e reproduzir informações, sendo construtivo, envolvendo exploração e formulação e raramente procedendo diretamente à seleção a partir de uma coleta. 


\subsection{Os atributos correspondentes aos sentimentos na recuperação de informações}

O quadro abaixo evidencia uma visão do ISP, mostrando os estágios em que é composto e os seus referidos elementos que são os sentimentos, as ações, pensamentos e finalmente, a tarefa identificada por Kuhlthau (1991) como adequada a cada etapa.

Continuação

Quadro 3 - Processo de Busca da Informação (ISP)

\begin{tabular}{|c|c|c|c|c|}
\hline Estágios do ISP & $\begin{array}{l}\text { Sentimentos comum a } \\
\text { cada estágio }\end{array}$ & $\begin{array}{l}\text { Pensamentos } \\
\text { comuns a cada } \\
\text { estágio }\end{array}$ & $\begin{array}{l}\text { Ações comuns a } \\
\text { cada estágio }\end{array}$ & $\begin{array}{l}\text { Tarefa apropriada de } \\
\text { acordo com o modelo de } \\
\text { Kuhlthau }\end{array}$ \\
\hline 1. Início & Incerteza & Generalizados & $\begin{array}{c}\text { Buscando } \\
\text { informações gerais }\end{array}$ & Reconhecer \\
\hline 2. Seleção & Otimismo & ----- & ---- & Identificar \\
\hline 3. Exploração & $\begin{array}{l}\text { Confusão / } \\
\text { Frustração / Dúvida }\end{array}$ & ----- & $\begin{array}{l}\text { Buscando } \\
\text { informações } \\
\text { relevantes }\end{array}$ & Investigar \\
\hline 4. Formulação & Clareza & Específicos / Claros & ----- & Formular \\
\hline 5. Coleta & $\begin{array}{l}\text { Senso de direção / } \\
\text { Confiança }\end{array}$ & Aumento do Stress & $\begin{array}{l}\text { Buscando } \\
\text { informações } \\
\text { focadas }\end{array}$ & Coletar \\
\hline 6. Apresentação & $\begin{array}{l}\text { Alívio / Satisfação ou } \\
\text { Frustração }\end{array}$ & Focado & $-\cdots---$ & Completar \\
\hline
\end{tabular}

Fonte: Kuhlthau (1991, p. 363, tradução nossa)

Esses processos influenciam diretamente as estratégias para a recuperação da informação, pois promovem aspectos cognitivos que são explorados com 0 objetivo final de alterar 0 conhecimento e, consequentemente, cresce a probabilidade de gerar conteúdo de qualidade, haja vista que para isso é necessário desenvolver esse procedimento de forma adequada e competente. No tocante do estudo será utilizado o processo sentimental, porque abarca por completo com a relação dos estágios, o mesmo não acontece com os pensamentos e ações.

Os estágios do modelo ISP desenvolvido por Carol Kuhlthau estão descritos de acordo com cada fase, conforme mostra o quadro 4.

Quadro 4 - Estágio e sentimentos de acordo com cada etapa do ISP

\begin{tabular}{|c|l|}
\hline Fase & \multicolumn{1}{c|}{ Descrição } \\
\hline Início & $\begin{array}{l}\text { Neste estágio, a pessoa se torna inicialmente consciente da falta de conhecimento ou entendimento. } \\
\text { Também é nesta etapa que as sensações de incerteza e apreensão são comuns. Neste ponto, as tarefas } \\
\text { são meramente de reconhecer as necessidades de informação. As ações frequentemente envolvem } \\
\text { possibilidades de discussão de tópicos e de acasos. }\end{array}$ \\
\hline Seleção & $\begin{array}{l}\text { Durante esta etapa a tarefa é identificar e selecionar tópicos gerais para serem investigados ou localizar } \\
\text { uma maneira de obtê-los. }\end{array}$ \\
\hline Exploração & $\begin{array}{l}\text { É caracterizada por sensações de confusão, de incerteza e de dúvida, que frequentemente aumentam } \\
\text { durante o decorrer deste período. Nesta etapa, o indivíduo busca por informações relevantes a respeito } \\
\text { de um tópico genérico. }\end{array}$ \\
\hline Formulação & $\begin{array}{l}\text { Nesta etapa, o estudante possui um direcionamento para o seu estudo. Para o ISP, este é considerado } \\
\text { um momento decisivo, pois o sentimento de incerteza diminui e a pessoa sente-se mais confiante. }\end{array}$ \\
\hline Coleta & $\begin{array}{l}\text { Neste período, o usuário já possui um senso de direção bem definido, sabendo que caminho irá tomar e } \\
\text { sente-se mais confiante. Outro aspecto que ocorre durante a etapa da "Coleta" é a maior interação do } \\
\text { usuário com os sistemas de informação. Esta característica ocorre de um modo mais efetivo durante esta }\end{array}$ \\
\hline
\end{tabular}




\begin{tabular}{|l|l|}
\hline & etapa, comparando-se a outros momentos do processo. \\
\hline Apresentação & $\begin{array}{l}\text { Esta é a fase conclusiva, que fecha o processo. Nesta parte do ISP são comuns sentimentos como alívio, } \\
\text { satisfação ou descontentamento. As ações realizadas vão envolver o resumo da pesquisa onde são } \\
\text { verificados o aumento da redundância e a diminuição da relevância nas informações encontradas. Nesta } \\
\text { fase é produzido o resultado de todo o processo de busca, o produto final, que poderá ser um texto, uma } \\
\text { apresentação oral, um artigo ou uma monografia. }\end{array}$ \\
\hline
\end{tabular}

Fonte: Kuhlthau (1991, p. 366, tradução nossa)

Este modelo de busca da informação pode ser aplicado em qualquer ambiente de pesquisa, porque passa por etapas que vão fazer com que o pesquisador, discente, docente e dentre outros encontre soluções para resolver os seus problemas informacionais; e, com isso, recuperar aquilo que é fundamental para desenvolver a sua pesquisa de forma mais satisfatória, e no final sentir se sentirá exitoso por conseguir completar o que foi proposto inicialmente.

Para um melhor entendimento desse processo, assevera-se que essa:

Abordagem cognitiva revelou que a busca por informações envolve diferentes estágio de conhecimento [...]. Este modelo, acrescentando uma dimensão afetiva, apresenta a busca da informação como um processo de construção de diminuição da incerteza à medida que aumenta a compreensão, incorporando o cognitivo com experiência afetiva comum no processo de busca e utilização da informação ${ }^{18}$ (KUHLTHAU; TAMA, 2001, p. 27, tradução nossa).

Na perspectiva de melhor abrangência no que diz respeito à busca de informação com qualidade, para o usufruto da mesma da melhor forma possível.

\subsubsection{A leitura como processo indispensável diante desse aspecto comportamental}

Face a face importante aspecto tratado, quanto à formação do indivíduo, a leitura sempre vai fazer parte do processo independentemente de qual estágio da vida a pessoa se encontre; seja na infância, adolescência ou vida adulta. Por ser um componente indispensável para o desenvolvimento intelectual e cientifico do ser humano.

A prática dessa atividade intelectual também é fundamental na qualificação do profissional, porque faz parte da atualização e, consequentemente, 0 instrumentaliza para adentrar no mercado de trabalho com qualidade, oferecendo mão-de-obra extremamente proficiente na execução das atividades, no âmbito de qualquer unidade de informação onde for exercer a profissão de bibliotecário.

O processo de busca informacional resulta-se no exercício da leitura, o que torna-se no uso das informações recuperadas (KUHLTHAU, 2004; WILSON, 1999), sendo precípuo para os usuários identificar seus déficits, objetivando angariar mais conhecimento ao seu intelecto; pois, segundo 
Souto (2010, p. 81): "assim, pode facilitar a identificação das reais necessidades de informação que motivaram o processo de busca de informação" e, por conseguinte a satisfação aumenta, o que possibilita a geração de mais conhecimento.

A leitura está incorporada à necessidade de informação, Taylor (1968, p. 182 apud SOUTO, 2010, p. 82, grifo nosso), identifica quatro níveis diante desse processo imprescindível, que são:

Visceral: um vago sentimento de insatisfação relacionado a uma necessidade não externalizada;

Consciente: descrição mental, com questões genéricas, vagas e, às vezes, ambíguas da questão, que causa a inquietação no indivíduo;

Formalizado: expressão racional da necessidade de informação, podendo ser representada em uma pergunta;

Adaptado: a questão, é às vezes, reformulada e apresentada ao sistema de informação.

Figueiredo (1996, p. 13, grifo nosso), tomando por base o grau de consciência em relação ao indivíduo, mostra uma categorização de três níveis para as necessidades de informação, que são as seguintes:

Necessidade expressa: é consciente e geralmente leva a um pedido por informação;

Necessidade não expressa: é sentida, mas não foi adequadamente expressada;

Necessidade não ativada: trata-se de uma necessidade latente.

Os níveis propostos pelos autores evidenciam que a informação, independentemente de qual área do conhecimento for acessada, requer um tratamento técnico adequado para proporcionar a seu usuário confiabilidade e satisfação, quando for recuperá-la e usá-la para fins culturais ou científicos. Destarte, este processo é parte integral da vida de qualquer indivíduo, pois: "estamos vivendo em um mundo com complexas transformações, onde a informação é imprescindível para a sobrevivência e o desenvolvimento da sociedade. Surge então a necessidade de entendermos o que é informação e como usufruir dela" (SILVA, P. 2008, p. 256), para podermos usufruir a mesma de maneira condizente e adequada na atual sociedade informacional que estamos inseridos.

\section{Apresentação e Análise dos Resultados}

No instrumento utilizado para viabilizar a pesquisa, o item 1 contempla a determinação do ano de ingresso dos acadêmicos no curso, apresentando alternativas que variam de ano de dois mil e oito (2008) até dois mil e onze (2011), entretanto consta da opção outro, a qual 
poderia ser assinalada, caso o aluno não pertencesse a nenhum dos anos referidos na questão. Em função disso, registrou-se informações de respondentes ingressos no ano de dois mil e quatro (2004), como podemos constatar no gráfico abaixo.

Gráfico 1 - Ano de ingresso dos discentes

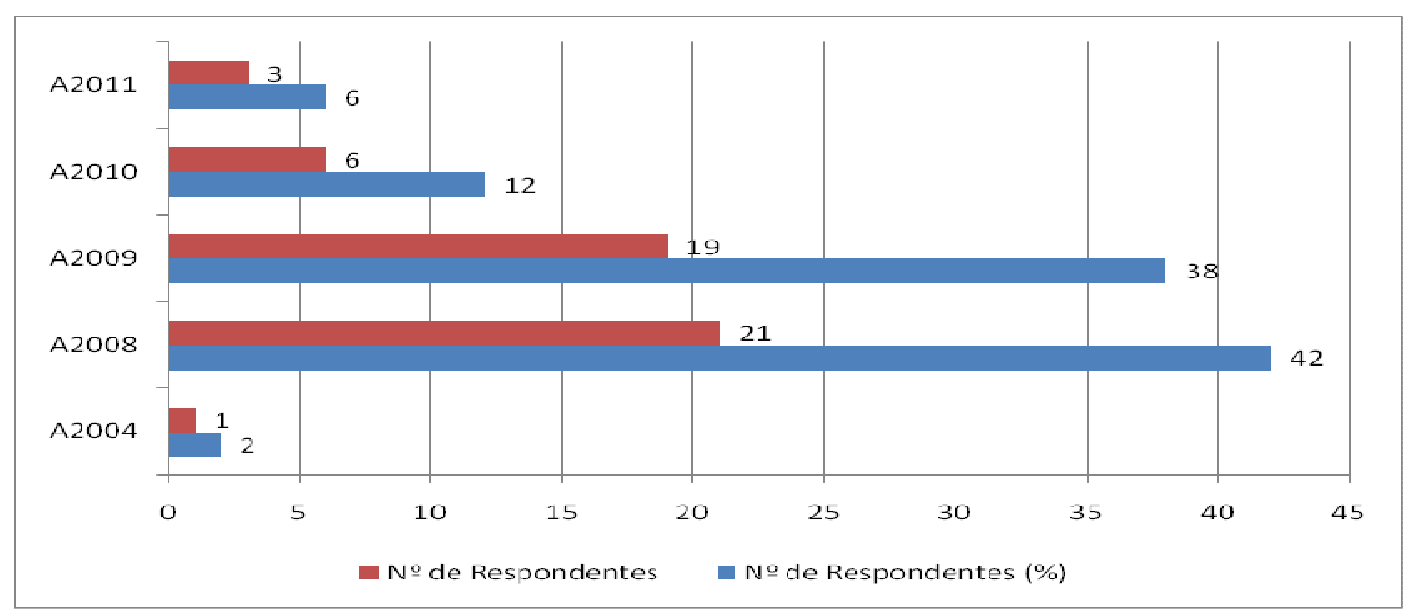

Fonte: Elaborado pelo autor (2012)

De acordo com os dados obtidos, verifica-se que a maior parte dos respondentes da pesquisa é formada por veteranos, pois a maioria dos questionários retornados concentrou-se entre os anos de 2008, (21) alunos, (42\%) e 2009 (19) acadêmicos, (38\%); em menor escala houve respondentes do ano de 2010 (6) discentes, (12\%); já, entre os calouros 2011, o preenchimento do questionário foi mais reduzido (3) alunos, $(6 \%)$; contudo, a menor expressão de respostas (1) estudante, (2\%) correspondeu aos alunos que estão em vias de jubilamento e que ingressaram no curso no ano de 2004.

Esse questionamento atendeu a necessidade informacional do elaborador do questionário por abarcar os anos que estão sendo cursados regularmente na FABIB e congrega um universo considerado constante para a tabulação dos próximos questionamentos.

No gráfico abaixo, é possível verificar a distribuição dos turnos de estudo, para se identificar em qual deles foram respondidos mais questionários.

Gráfico 2 - Turnos de estudo dos respondentes.

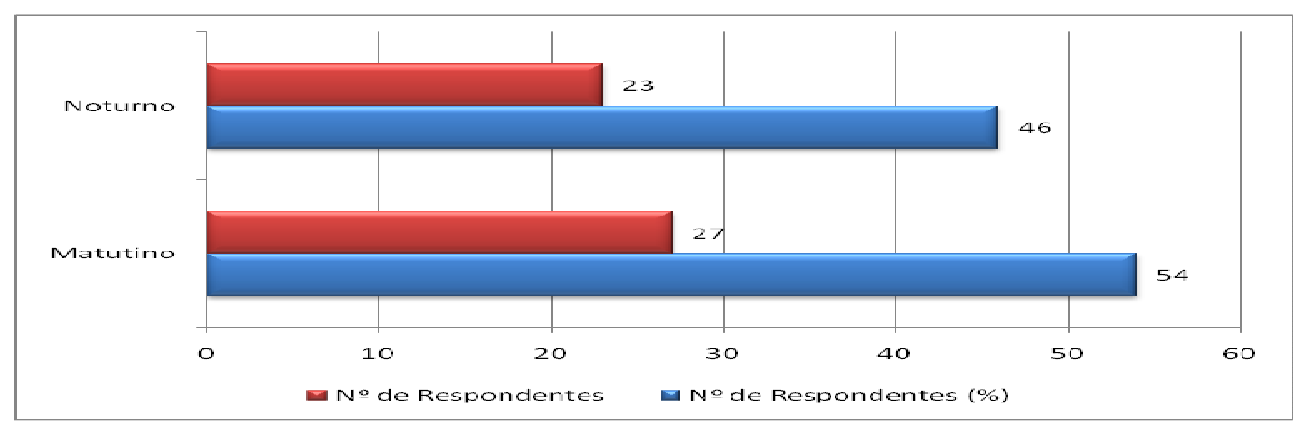

Fonte: Elaborado pelo autor (2012) 
Assim sendo, constatou-se que a maioria dos respondentes são discentes do turno matutino, perfazendo um montante de vinte e sete (27) alunos, cinquenta e quatro por cento (54\%); enquanto que o turno noturno abarcou vinte e três (23) discentes, quarenta e seis por cento (46\%) do universo de graduandos perguntados. Nesse contexto, é possível notar uma diferença de doze por cento (12\%) no tocante dos respondentes da pesquisa em favor dos acadêmicos que estudam pelo turno da manhã em relação aos da noite. Perante ao comportamento informacional o resultado demonstra que os graduandos que estudam pela manhã foram mais ativos em colaborar com a pesquisa.

O gráfico seguinte é destinado a determinar o gênero dos respondentes, e através do qual patente a supremacia feminina no curso, pois, embora a presença masculina tenha se intensificado, principalmente no transcorrer do Século XXI, as mulheres ainda constituem a maioria absoluta nessa graduação, o resultado mostra onze (11) alunos, correspondendo uma porcentagem de vinte e dois por cento (22\%) do gênero masculino e trinta e nove (39) alunas, resultando setenta e oito por cento $(78 \%)$ do sexo feminino.

Percebe-se que o sexo masculino têm uma necessidade de adentrar no curso mais ênfase por motivos que englobam: o mercado de trabalho que é promissor e pelo fato das TIC's estarem em evidência na atuação do bibliotecário e dentre outras razões, mas, o paradigma da graduação ter número maior de mulheres provavelmente não vai ser superado por motivos históricos.

\section{Gráfico 3 - Gênero dos respondentes}

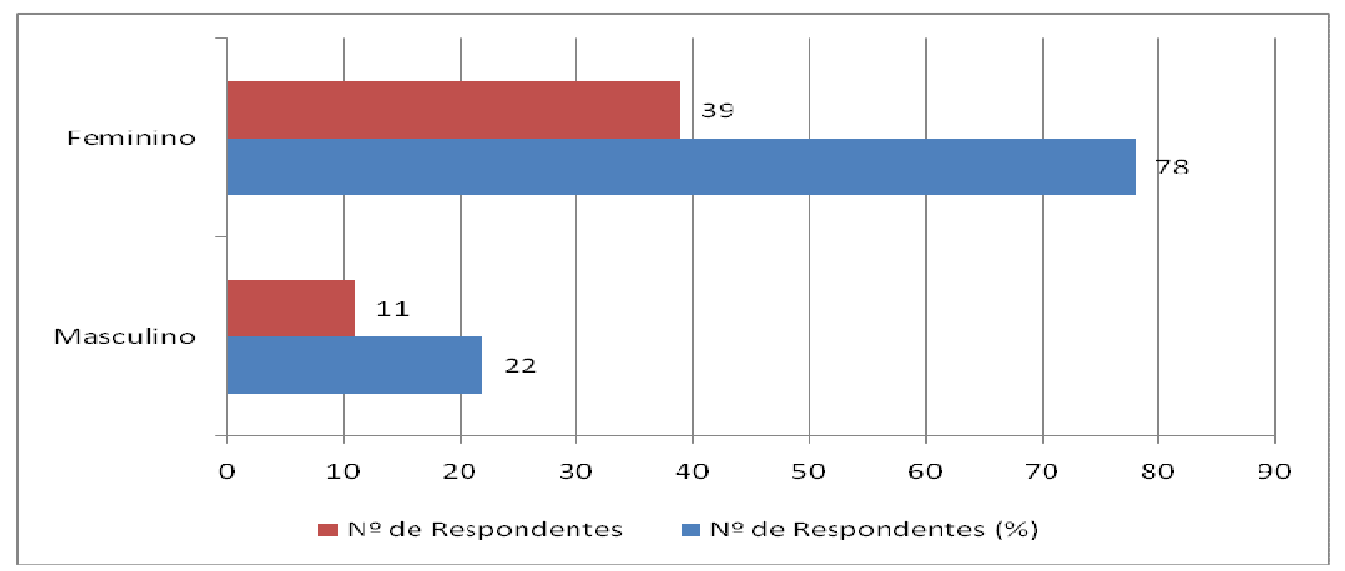

Fonte: Elaborado pelo autor (2012)

No quarto questionamento, investigou-se o nível de conhecimento dos estudantes acerca das TIC's. O gráfico expresso a seguir demonstra como está a situação atual, a qual, reflete diretamente a conjectura dos estudos desenvolvidos e a qualidade das pesquisas realizadas. 
Gráfico 4 - Conhecimento acerca das TIC's.

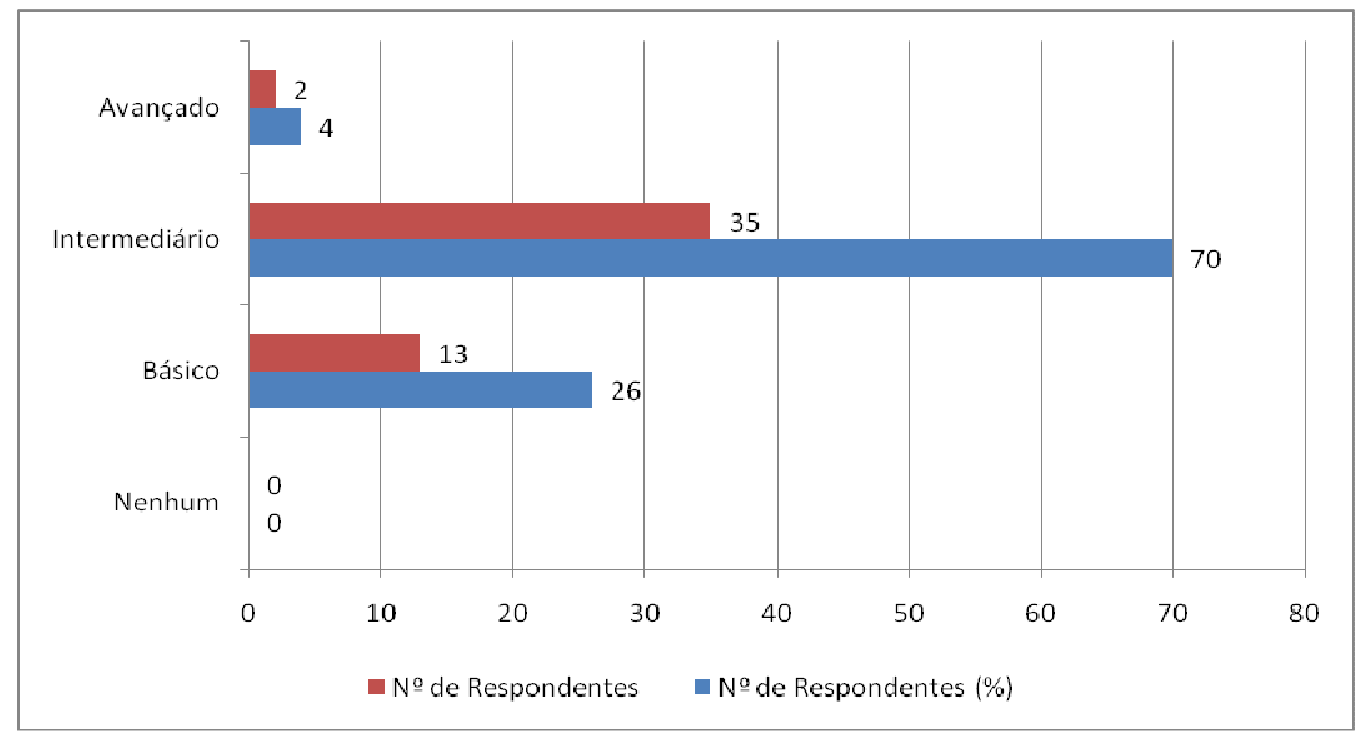

Fonte: Elaborado pelo autor (2012)

Em conformidade com os dados extraídos, treze (13) alunos responderam que seu grau de conhecimento é básico, correspondendo a vinte e seis por cento (26\%); já trinta e cinco (35), setenta por cento (70\%) disseram que o seu grau de instrução é intermediário, e somente dois (2) alunos marcaram a opção avançado, o que gerou quatro por cento $(4 \%)$ do total. A opção nenhum não foi assinalada pelos respondentes.

Esse resultado sugere que os graduandos estão bem atualizados no que diz respeito à utilização das TIC's, pois o conhecimento sobre essas tecnologias são fatores preponderantes para atender a necessidade de informação e para auxílio nos estudos e realização de suas pesquisas ou como suporte no atendimento aos usuários, pois, quase a totalidade de alunos realizam estágios em bibliotecas, centros e unidades de informação da capital paraense.

A questão subsequente tratou do aspecto do hábito de leitura, e procurou-se investigar nesse questionamento se os discentes entendem que essa prática interfere diretamente na qualificação e atualização profissional do bibliotecário, haja vista que a graduação se apóia na leitura como um dos mais importantes pilares da sua história. Os resultados dessa questão estão dispostos no gráfico abaixo. 
Gráfico 5 - Verificação do hábito de leitura.

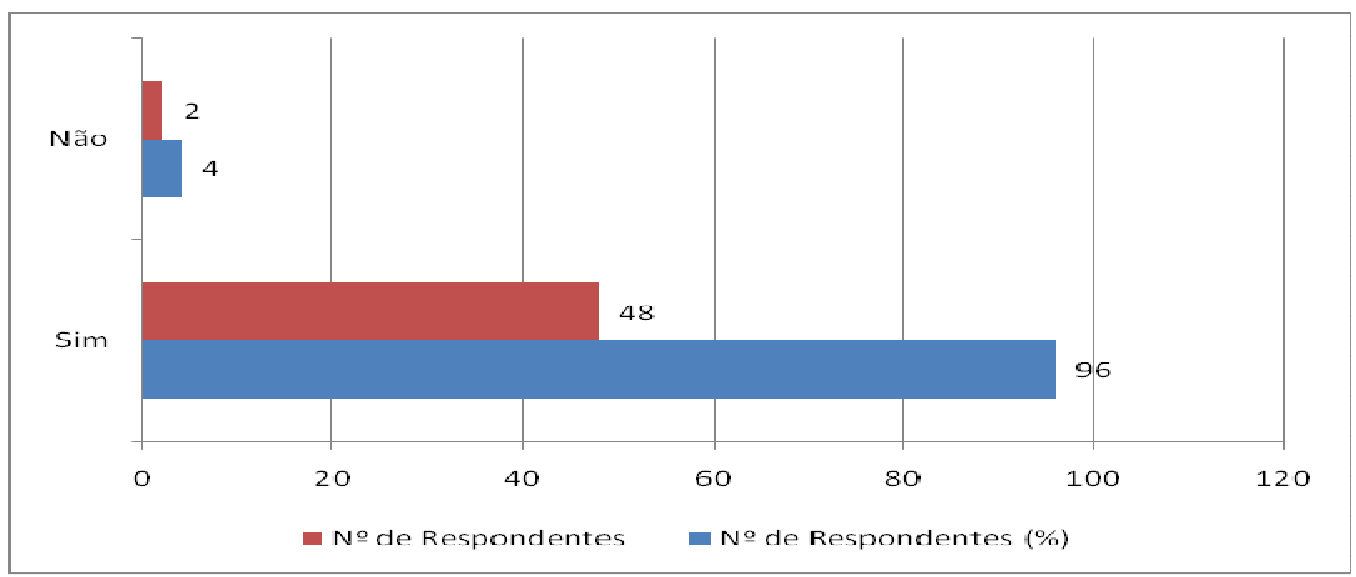

Fonte: Elaborado pelo autor (2012)

O resultado mostrou-se bastante satisfatório, uma vez que quarenta e oito (48) alunos afirmaram cultivar o hábito de leitura para o aprendizado, o que corresponde a uma porcentagem bem significativa de noventa e seis por cento ( $96 \%$ ) do universo amostral; e apenas dois (2) indivíduos, ou seja, quatro por cento (4\%) responderam que não exercem essa prática essencial para a vida de qualquer pessoa.

Esse resultado demonstra a conscientização dos acadêmicos em praticarem a leitura, seja científica ou literária, para fins de provimento de conhecimento e futura geração do mesmo, fomentando, assim, a produção acadêmica e contribuindo de forma condizente para a literatura biblioteconômica, seja em forma de artigos, papers, relatos de experiências, relatos de pesquisas, dentre outros tipos de trabalhos acadêmicos. E consoante ao comportamento informacional proposto por Wilson, a leitura é o último passo da necessidade de informação.

A indagação realizada na sexta questão refere-se ao meio de recuperação da informação que os discentes fazem uso com mais frequência. O gráfico 6 mostra o resultado desse questionamento em aspectos quantitativos.

Gráfico 6 - Meio de recuperação da informação usado pelos discentes

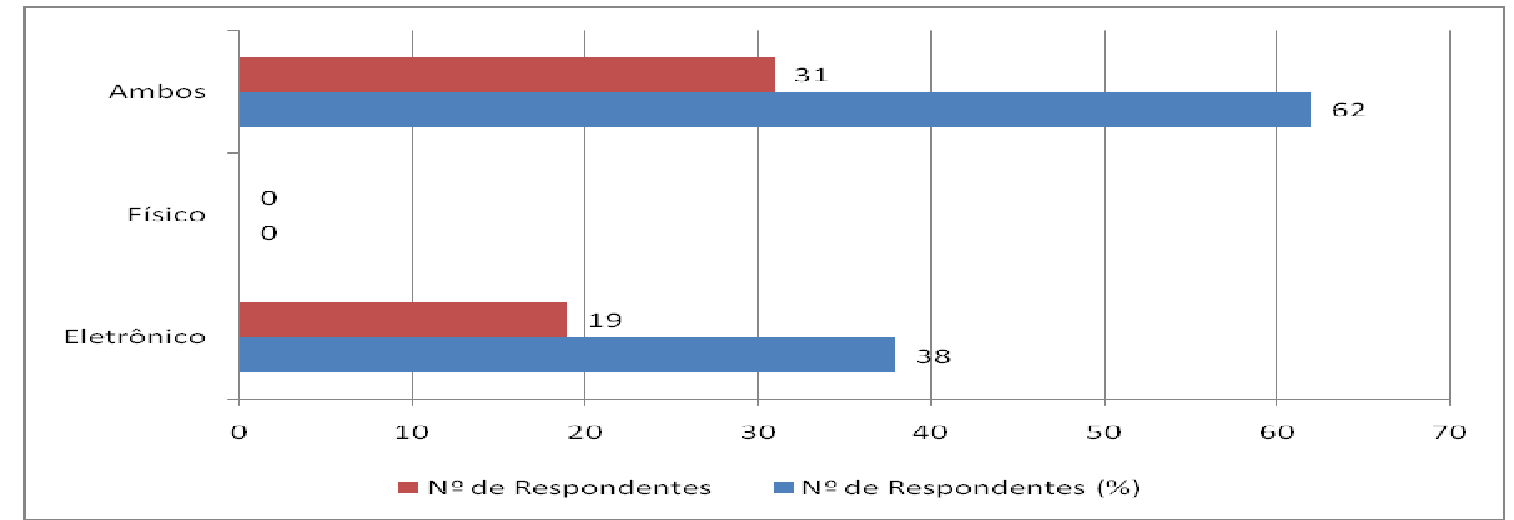

Fonte: Elaborado pelo autor (2012) 
Diante dos resultados alcançados, observa-se que dos pesquisados trinta e um (31) responderam que tanto o modo físico quanto o eletrônico são utilizados de modo equitativo para a realização de pesquisas acadêmicas, o que representa sessenta e dois por cento $(62 \%)$ dos discentes questionados. Isso significa que, apesar das TIC's serem fortes aliadas na conjectura da busca informacional, a informação registrada no modo impresso representa um grande contributo no que se refere ao acesso e à recuperação da informação.

A opção eletrônico foi assinalada por dezenove (19) acadêmicos, correspondendo a um percentual de trinta e oito por cento (38\%) do total de respondentes. Esse fato deve-se à imensidão de oportunidades que a internet oferece aos seus usuários, no sentido da obtenção informacional, e pela mesma ser de fácil acesso; e também pela sua fundamental importância no que se refere à atualização profissional, auxiliando de modo essencial na educação continuada, sendo que o discente de Biblioteconomia precisa adquirir esse conhecimento, que deve ser desenvolvido ao longo da sua graduação.

Ressalta-se que a opção de resposta físico não foi assinalada, pois, em virtude da facilidade propiciada pelas tecnologias informacionais, 0 meio físico, muitas vezes, é relegado a segundo plano no momento da elaboração das pesquisas.

A pergunta também apresenta um caráter assertivo, pois, além de marcar a opção, o aluno tinha que justificar sua resposta e, concernente aos que responderam a opção eletrônica, a justificativa marcante dentre os indivíduos foi a possibilidade de acesso mais veloz à informação que o segmento virtual oferece. Cabe destacar uma resposta que complementa de maneira adequada essa interpretação.

A recuperação em meio eletrônico é mais rápida, facilitando a agitação do dia a dia (RESPONDENTE 1).

Por ser mais prático (RESPONDENTE 2).

Pela facilidade em acessar (RESPONDENTE 3).

No que diz respeito às pessoas que assinalaram a opção ambos, a justificativa presente foi que, apesar da praticidade conferida pelo acesso eletrônico, o modo físico tem seu uso respaldado por assegurar credibilidade à informação. Desta feita, se faz mister as unidades de informação, os centros de informação, as bibliotecas e demais órgãos centrados no aspecto informacional, aplicarem critérios comprometidos com a qualidade no momento em que as informações destas instituições são disponibilizadas aos seus usuários. Um comentário bem condizente com essa questão, é transmitido a seguir:

Em relação ao eletrônico é uma ferramenta mais rápida e prática, e em relação a agilidade, enquanto que o físico estabelece mais confiabilidade (RESPONDENTE 4). 
As vezes para comprovar a veracidade, ou mesmo para complementar o trabalho a assim tornar o mesmo mais aprofundado (RESPONDENTE 5).

Simples fato de buscar fontes seguras em meio tradicional (livro) e ter o fator tempo favorecido na pesquisa on-line em meio eletrônico (RESPONDENTE 6).

Partindo para o próximo questionamento, inquiriu-se quanto à utilização de outros idiomas para a realização dos estudos e pesquisas acadêmicas por meio de suas fontes informacionais, haja vista a importância da compreensão do conhecimento em outras línguas, principalmente em inglês (que é um idioma universal e o mais aceito no universo científico). Na Biblioteconomia e em todas as áreas do saber humano, o conhecimento de outros idiomas é fundamental, em virtude de agregar qualificação e valorização ao profissional, especialmente ao bibliotecário.

O gráfico 7 expõe os resultados concludentes relativos a essa questão, sendo que a mesma também dispunha um cunho assertivo, para justificar com mais precisão as respostas obtidas.

Gráfico 7 - Utilização de fontes de informação em outros idiomas

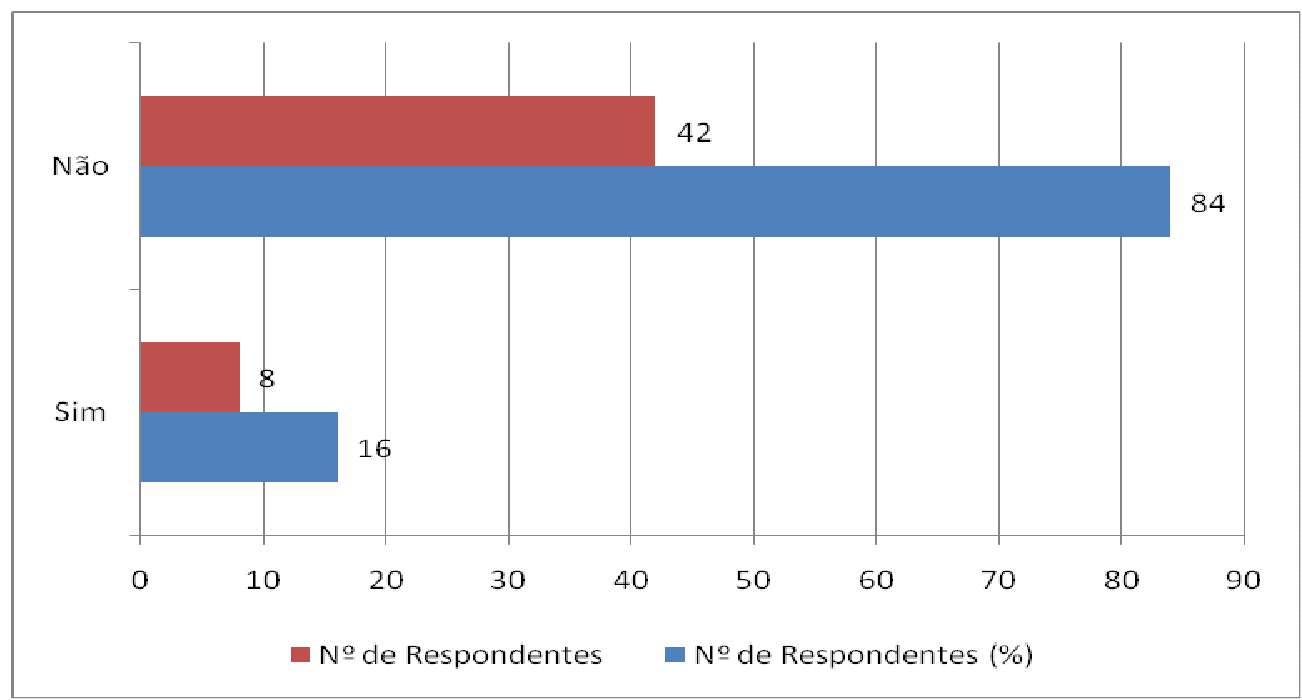

Fonte: Elaborado pelo autor (2012)

Face às respostas inferidas, tem-se que quarenta e dois (42) discentes responderam que não fazem uso de fontes de outros idiomas para desenvolverem suas respectivas pesquisas, o que representa oitenta e quatro por cento (84\%) do universo amostral, abrangendo um índice 
bastante alto no que tange a não utilização das fontes de informações em idiomas diferentes do português, o que resulta em uma barreira pessoal diante do comportamento informacional, objeto de proposta de Wilson; já o quantitativo que respondeu sim à questão corresponde a somente oito (8) acadêmicos, gerando ,assim, um resultado de dezesseis por cento (16\%) da totalidade pesquisada.

A justificativa preponderante para quem assinalou a opção não, foi que a captação de conhecimento em outra língua configura-se num obstáculo, por influenciar negativamente, o que agrega em barreira pessoal, aumentando o grau de dificuldades de aprendizagem e comprometendo o entendimento da informação disponibilizada. Vale ressaltar um comentário feito por um discente:

Geralmente a língua dificulta a plena compreensão da informação (RESPONDENTE 7).

Por não possuir estudos em outras línguas (RESPONDENTE 8).

Por não ter domínio de outras línguas e por não ter acesso (RESPONDENTE 9).

Para quem assinalou a alternativa sim, ficou evidente a importância do entendimento global do conteúdo informacional no processo de estudos e, consequentemente, da realização da leitura em outro idioma, principalmente em inglês. Abaixo é reproduzida uma resposta que condiz de maneira proficiente com essa análise qualitativa.

É primordial a nossa adesão em relação as fontes em outros idiomas. Devemos acompanhar a evolução e oferecer um trabalho de qualidade aos diferentes usuários (RESPONDENTE 10).

A maioria das bases de dados estão em outro idioma (RESPONDENTE 11).

Quando necessito para compor um trabalho acadêmico (RESPONDENTE 12).

A discrepância observada nos resultados (Não - 84\% / Sim - 16\%), além de preocupante, demonstra que se faz necessária a conscientização por parte dos discentes de Biblioteconomia de aprender outro idioma é de imperativo no tocante a sua própria qualificação profissional, bem como quanto à eficiente prestação de auxílio para os seus consulentes na 
realização de pesquisas com alto grau de excelência. Portanto, a capacitação na fluência de outras línguas é imprescindível, haja vista, para fomentação da pesquisa científica com qualidade o portal de periódico da Coordenação de Aperfeiçoamento de Pessoal em Nível Superior (CAPES) é referencia mundial por constar de mais de cinco mil (5.000) periódicos, livros e outros materiais, com padrão alto de qualidade científica, no seu banco de dados, os quais, em sua grande maioria, são disponibilizados em idioma inglês.

Na Biblioteconomia, temos, ainda, a Dewey Decimal Classification (CDD), que é uma ferramenta referencial indispensável para os bibliotecários e estudantes de Biblioteconomia em termos de Classificação, impressa totalmente em inglês, além de bases de dados, periódicos eletrônicos, livros e a produção científica de autores internacionais, elementos estes bastante significativos na área biblioteconômica.

O próximo questionamento diz respeito às fontes utilizadas com mais frequência, no intuito de se recuperar a informação. No gráfico, a seguir tem-se o resultado quantitativo, cabendo informar que a questão também requer a elaboração de justificativa.

Gráfico 8 - Fontes que suprem com mais impacto a necessidade informacional

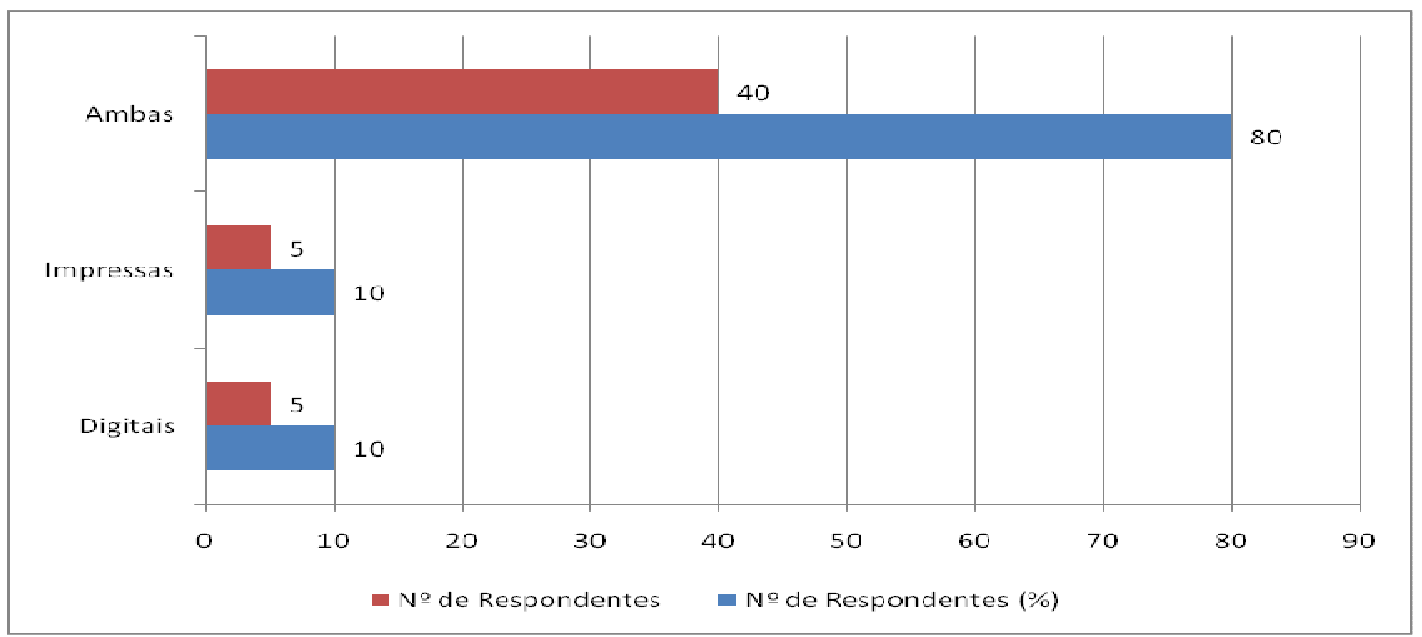

Fonte: Elaborado pelo autor (2012)

Os resultados obtidos mostram que tanto as fontes impressas quanto as digitais possuem o mesmo peso de significância na conjectura do aprendizado dos discentes de Biblioteconomia, pois cinco (5) deles assinalaram a opção digitais, o que corresponde a dez por cento $(10 \%)$ da população estudada; e o mesmo quantitativo (5) marcou a opção impressas, resultando no mesmo percentual (10\%). Essa situação tende a uma mudança de paradigma referente ao uso de ferramentais tecnológicas para a obter informações, pois, já foram realizados estudos que identificaram que as ciências exatas ou naturais se utilizam mais de expedientes eletrônicos, principalmente no que diz respeito ao uso com grau elevado de periódicos científicos do que as áreas de ciências humanas. 
Crespo e Caregnato (2006, p. 30), realizarem um estudo nesse rumo e concluíram que "esse direcionamento de suas práticas de comunicação para o uso intenso dos periódicos é característico das áreas científicas duras, o que as diferencia das ciências humanas e sociais, nas quais o livro ocupa posição central", reforçado com os estudos de Meadows (1999, p. 152) que prova essa situação ao demonstrar que:

[...] a partir das diferentes práticas de citações adotadas pelos pesquisadores, explicando que $82 \%$ das citações dos trabalhos dos cientistas das áreas chamadas duras eram oriundas dos periódicos, enquanto para as ciências sociais o percentual era de somente $29 \%$. Quanto aos livros, a situação era oposta, sendo que, nas ciências duras, essa fonte era utilizada em $12 \%$ dos trabalhos e, nas ciências, sociais era usada em $46 \%$ das referências.

Diante das assertivas escritas pelos graduandos, quem optou pela alternativa digitais, justificou relatando que as informações são recuperadas de maneira mais célere, reduzindo consideravelmente 0 tempo de realização das pesquisas, o que resulta na quarta lei de Ranganathan - poupe o tempo do leitor - e proporcionando mais praticidade na captação das informações. Cumpre destacar uma justificativa descrita abaixo, para embasar essa interpretação:

Pela facilidade em localizar o que desejo no menor tempo possível (RESPONDENTE 13).

Pelo fato de the proporcionar com mais rapidez e um campo enorme dos mais variados assuntos (RESPONDENTE 14).

Devido as bases de dados (RESPONDENTE 15).

Os alunos que marcaram a opção impressas abordaram com ênfase 0 aspecto de credibilidade conferido pelo formato impresso, bem como mencionaram o aspecto de comodidade proporcionado por este meio quando da absorção de conteúdos, o que propicia a realização de estudos com mais tranquilidade e com melhor proficiência. Dentre as assertivas registradas, cabe ressaltar uma na íntegra:

Porque posso levar o material para estudar em casa com mais tranquilidade e também tem melhor visualização (RESPONDENTE 16).

Prefiro as fontes impressas, pois posso levar para ler aonde eu for, além de poder sublinhar pontos relevantes (RESPONDENTE 17). 
Porque nem todos os documentos estão em formato digital, além de passar maior confiança (RESPONDENTE 18).

Já os que assinalaram a opção ambas, quarenta (40) alunos, oitenta por cento $(80 \%)$ - quase a totalidade dos graduandos - ao justificarem sua escolha, foram praticamente unânimes em afirmar que em razão de estarmos inseridos numa sociedade informacional tecnológica, cuja produção acontece de maneira rápida e a todo instante em pleno Século XXI, e o emprego das TIC's é de importância primordial para a elaboração de estudos e pesquisas científicas; e alegaram, ainda, que utilizam concomitantemente ambos os meios (digital e impresso) pela rapidez da busca de informações no segmento disponível eletronicamente, mas que também consultam os registros impressos pela credibilidade e comodidade que os mesmos proporcionam no momento da leitura dos documentos obtidos. A seguir revela-se uma declaração bastante pertinente a essa questão:

Uso as fontes digitais pela velocidade da recuperação e os impressos pela credibilidade da informação (RESPONDENTE 19).

As digitais por estarem mais acessíveis, ou seja, acessada em vários lugares. Impressas por motivos de tradição, o simples hábito de manuseio de papel (RESPONDENTE 20).

Atualmente devemos recorrer a todos os meios que possam nos auxiliar com as informações (RESPONDENTE 21).

O próximo questionamento diz respeito aos sentimentos que acometem os discentes depois da realização de pesquisas de cunho acadêmico. O gráfico ilustra os resultados induzidos da questão proposta. Gráfico 9 - Sentimentos manifestados após o processo da realização de pesquisa

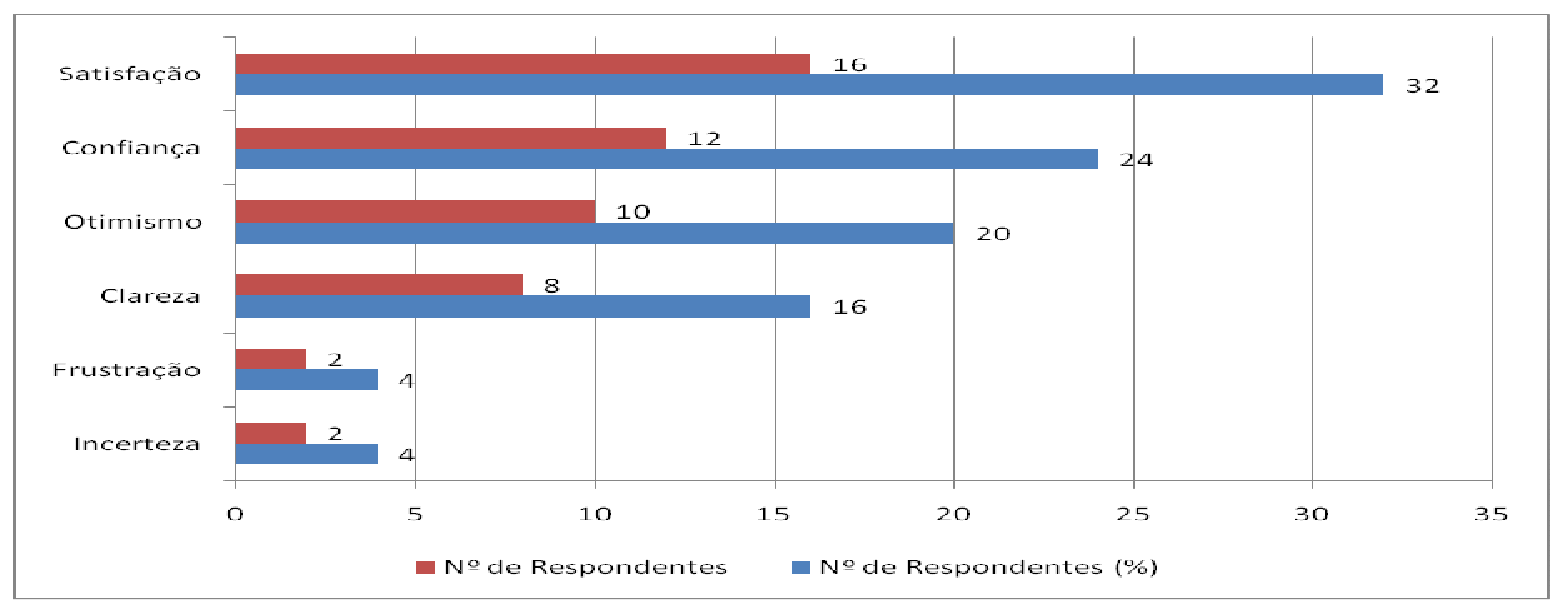

Fonte: Elaborado pelo autor (2012) 
Diante dos resultados auferidos, tem-se que dezesseis (16) dos pesquisados responderam sentir satisfação, o que corresponde a última etapa do ISP, sexto estágio (apresentação), um fator bastante positivo no que concerne à competência durante a recuperação da informação, equivalendo a trinta e dois por cento (32\%) do total; doze (12) deles afirmaram ter confiança, que é a quinta etapa do estágio (coleta), representando vinte e quatro por cento (24\%); oito (8) marcaram a alternativa clareza, quarta etapa do estágio (formulação) configurando dezesseis por cento (16\%); dois (2) discentes assinalaram a opção frustração, terceira fase (exploração) correspondendo a quatro por cento $(4 \%)$; a alternativa otimismo, segunda fase do processo (seleção) foi marcada por dez (10) alunos, representando vinte por cento $(20 \%)$; e, finalmente, a opção incerteza, que tem na sua correspondência a primeira fase do ISP (início), foi respondida por dois (2) acadêmicos, resultando em quatro por cento $(4 \%)$ dos estudantes questionados.

Os estudantes seguiram a seguinte ordem diante dos estágios desenvolvidos por Kuhlthau, no ano de 1991, que está demonstrado no quadro a seguir:

Quadro 5 - Estágios do ISP x Estágios percorridos pelos estudantes

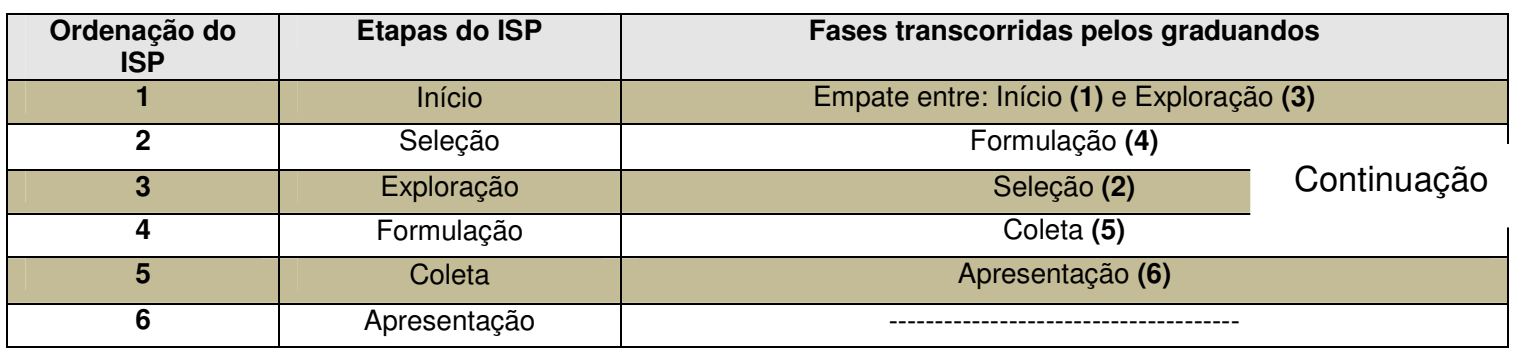

Fonte: Elaborado pelo autor (2012)

Dos resultados revelados, infere-se que os estudantes desenvolvem suas pesquisas por consequência da práxis acadêmica, e, ao final da realização das mesmas, geralmente o sentimento por eles manifestado é o de satisfação.

Esse sentimento constitui-se num aspecto de grande relevância, que contempla a perspectiva de execução de pesquisas mais exitosas, haja vista, o graduando ficar mais entusiasmado se 0 seu objetivo informacional for almejado com êxtase e qualidade. Isso também interfere diretamente em sua atuação profissional, em virtude do atendimento aos usuários, principalmente no setor de referência, ser realizado com mais eficácia e, assim, a informação consegue ser transmitida de maneira condizente e qualificada.

O resultado exposto demonstra ser valido o ISP elaborado por Kuhlthau em 1991, pois na correspondência com os estágios propostos no modelo, conclui-se que as fases estão sendo obedecidas de maneira quase harmoniosa.

As próximas questões são de cunho aberto, ou seja, são questionamentos em que os discentes respondem de maneira dissertativa. 
No que compete ao item 10, indagou-se quais as dificuldades frequentemente enfrentadas pelos graduandos em se tratando da utilização das TIC's para provimento na recuperação da informação.

$\mathrm{Na}$ análise das respostas, foi possível verificar que as principais barreiras a se enfrentar correspondem ao manuseio dessas tecnologias, o que gera uma barreira pessoal de procedência cognitiva por conta do desconhecimento de ferramentas que possibilitem o melhoramento na qualidade das pesquisas realizadas.

Outro empecilho destacado pelos alunos foi o desconhecimento de outro idioma, aspecto cognitivo, tornando-se como obstáculo pessoal, haja vista a produção científica ser considerada de maior relevância quando expressa em outra língua, principalmente a inglesa.

Mais uma dificuldade citada diz respeito à credibilidade das fontes encontradas, que se configura como barreira relativas as fontes, pois, para usá-las de maneira correta, além da realização de uma leitura perspicaz do material informativo (artigos, livros, capítulos de livros dentre outros), se faz necessário avaliar as fontes informacionais de forma criteriosa, contribuindo nesse aspecto reservou-se um capítulo desse trabalho acadêmico no qual se orienta como essa análise deve ser realizada, esse levantamento foi baseado em autores consagrados na área biblioteconômica.

Essas respostas apontam para uma necessidade premente de obterse um significativo melhoramento no que se refere ao manuseio dos recursos tecnológicos, no sentido de se conhecer o que a web concede aos seus usuários, pelo fato da mesma oferecer um amplo leque quantitativo de opções para a obtenção da informação. Desta feita, o futuro bibliotecário deve identificar pelo menos as principais ferramentas disponíveis, a fim de que possa auxiliar seus consulentes de forma proficiente, no intuito de fornecer aos mesmos serviços de alto nível de qualidade durante sua atuação profissional.

Abaixo tem-se uma amostra das justificativas dadas, a qual reflete esse quadro:

A maior barreira é entender outros idiomas também não saber manusear as ferramentas disponíveis (RESPONDENTE 22).

As vezes na forma incorreta de buscar ou por falta de orientação ou mesmo por falta de atenção (RESPONDENTE 23).

A credibilidade das fontes (RESPONDENTE 24).

A próxima indagação é referente aos periódicos eletrônicos em Biblioteconomia e Ciência da Informação, que são utilizados de maneira corrente por ocasião dos estudos e na elaboração de trabalhos de segmento acadêmico. O gráfico a seguir demonstra o resultado dessa discussão, em que os acadêmicos relataram quais são essas revistas. 
Gráfico 10 - Periódicos eletrônicos mais utilizados nos estudos pelos estudantes de Biblioteconomia

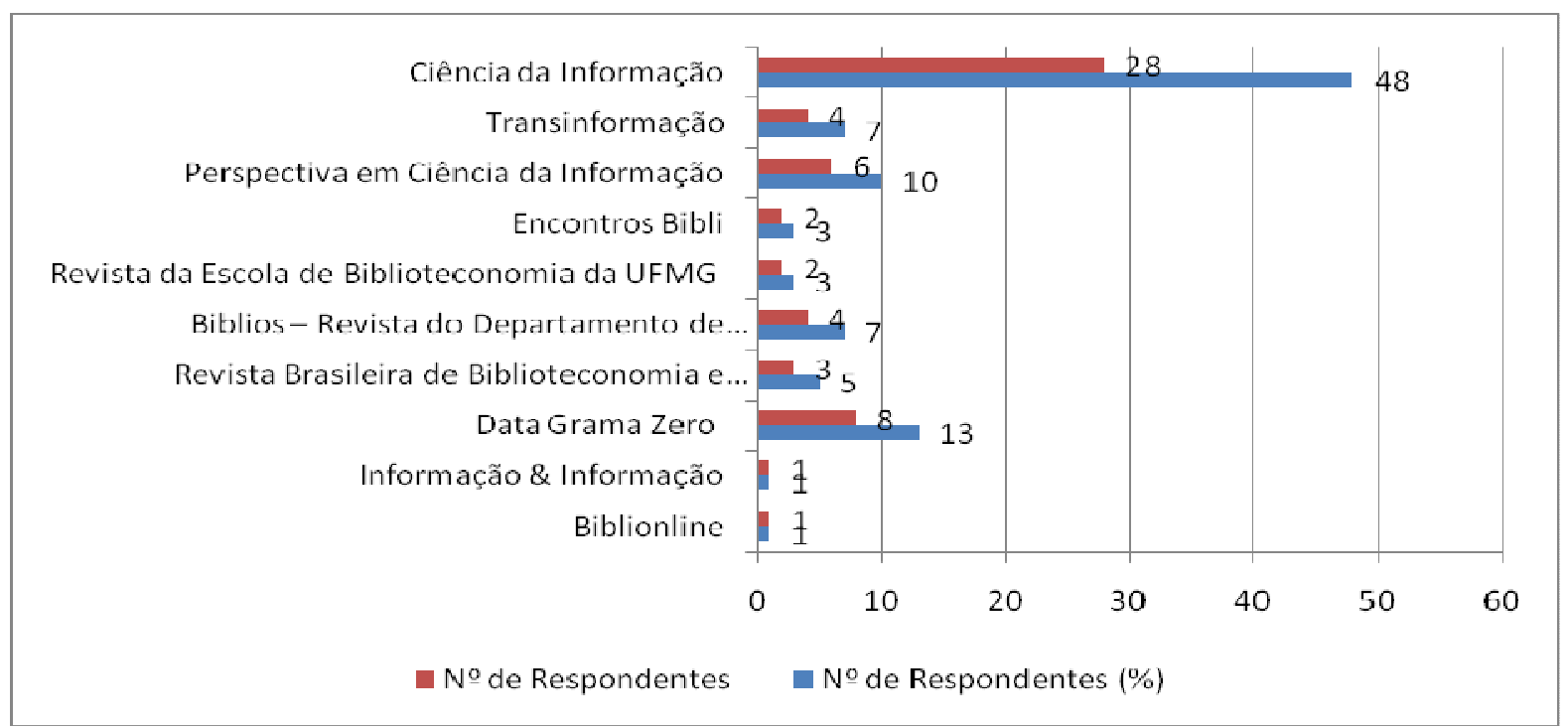

Fonte: Elaborado pelo autor (2012)

Diante do exposto nas informações obtidas, foram computados num total dez (10) periódicos, com um número de citações de cinquenta e nove (59) e deste montante percebeu-se que a publicação intitulada Ciência da Informação foi mencionada por vinte e oito (28) vezes, correspondendo a quarenta e oito por cento $(48 \%)$ de indicações, logo a seguir Data Grama Zero oito (8), (13\%); Perspectiva em Ciência da Informação seis (6), (10\%); Transinformação quatro (4), (7\%); Revista Brasileira de Biblioteconomia e Documentação (3), (5\%); Biblios - Revista do Departamento de Biblioteconomia e História quatro (4), (7\%); Encontros Bibli (2), (3\%); Revista da Escola de Biblioteconomia da UFMG (2), (3\%); Biblionline (1), (1\%) e Informação \& Informação (1), (1\%), o que reflete que essa revista eletrônica é a mais conhecida e conceituada da área de Biblioteconomia e Ciência da Informação, e conforme estudos realizados anteriormente, vem a "[...] ser a publicação de maior visibilidade e prestígio no cenário brasileiro" (SILVEIRA; SILVA, Fábio; CÔRREA, 2010, não paginado).

Todavia, sem demérito a mesma, além esta revista no universo tecnológico podemos recuperar uma quantidade consideravelmente grande de periódicos, o que propicia mais alternativas de pesquisas e consequentemente, uma melhor fundamentação no momento da realização de trabalhos acadêmicos.

Cabe ressaltar que os periódicos citados possuem Conceito Qualis e estão distribuídos no quadro a seguir: 
Quadro 6 - Conceito Qualis dos periódicos de Ciência da Informação citados na pesquisa

\begin{tabular}{|l|c|}
\hline \multicolumn{1}{|c|}{ Periódico } & Estrato \\
\hline Biblionline & C \\
\hline Informação \& Informação & B3 \\
\hline Data Grama Zero & B2 \\
\hline Revista Brasileira de Biblioteconomia e Documentação & B4 \\
\hline Biblios - Revista do Departamento de Biblioteconomia e História & B4 \\
\hline Encontros Bibli & B2 \\
\hline Perspectivas em Ciência da Informação ${ }^{19}$ & A2 \\
\hline Transinformação & B2 \\
\hline Ciência da Informação & A2 \\
\hline
\end{tabular}

Fonte: Coordenação de Aperfeiçoamento de Pessoal em Nível Superior ([20--], não paginado)

Algumas respostas foram desconsideradas, pois mencionavam publicações que não se enquadram na categoria periódicos. Parte dos estudantes arrolaram equivocadamente como periódicos tais como: o portal da CAPES, Scientific Electronic Library Online (SCIELO) e Google Acadêmico, os quais não configuram na conjectura da análise realizada, destaca-se que a Revista de Biblioteconomia da UFMG, "[...] que teve seu título alterado em 1996 para Perspectivas em Ciência da Informação, editada pela Escola de Ciência da Informação da UFMG" (ANDRADE, E.; OLIVEIRA, M., 2005, p. 42). Essas respostas levam a identificar um comportamento "negativo" em termos de conhecimento acerca dessa tecnologia informacional.

Convém lembrar dos periódicos publicados em outros idiomas, que não foram citados no questionamento, sobretudo em inglês, ocasionam uma barreira de ordem pessoal com aspecto cognitivo perante 0 transcurso do comportamento informacional, haja vista o levantamento realizado em um capítulo referente a esses recursos, que consistem, na sua maioria, de artigos científicos, principalmente de idioma inglês para fomentação da leitura acadêmica e são de importância ímpar na vida acadêmica do graduando.

A penúltima questão respondida pelos discentes diz respeito à importância da necessidade da leitura no contexto da vida acadêmica, onde se perguntou aos mesmos qual a relevância desse hábito em sua formação.

Os respondentes foram unânimes em afirmar que sem leitura não há desenvolvimento pessoal, e bem como torna-se difícil realizar e também não tem como desenvolver trabalhos de segmentação científica de qualidade, o que atrapalha sobremaneira o processo de aprendizagem, em razão da leitura ser essencial na qualificação profissional, ainda mais para os alunos que cursam uma graduação que tem o termo livro inerente a sua significação.

As TIC's estão presentes para facilitar o acesso a materiais que constituem textos que vão propiciar essa atualização de cunho 
profissional. Vale salientar duas respostas de indivíduos que abrangem essa situação de maneira condizente:

Ela é a chave do conhecimento e a base para buscar as respostas para nossas necessidades e concretizar nossos objetivos (RESPONDENTE 25).

A leitura vem ajudar no meu progresso acadêmico, ampliando minha visão dentro de minha área, como conhecimento geral (RESPONDENTE 26).

A leitura abre horizontes nos diversos assuntos e assim ajuda na realização de pesquisas (RESPONDENTE 27).

No âmbito do ensino superior, assim como em todas as etapas da vida do aluno, que inicia desde o jardim de infância, a leitura deve se fazer presente de modo constante para, consequentemente, contemplar a formação pessoal do indivíduo de modo proficiente e eficaz.

No último questionamento indagou-se a respeito de como os estudantes entendam que seja o comportamento no processo de busca da informação. A maioria das respostas foi no sentido de como deve ser realizada essa recuperação informacional, abordando-se o critério de filtragem diante do referido processo. Merecem destaque três (3) respostas condizentes com essa interpretação qualitativa:

Entendo como sendo o indivíduo ter consciência sobre a necessidade da informação, efetuando dessa forma, um critério para a filtragem da mesma (RESPONDENTE 28).

De que forma devemos buscar, ou seja, procurando em fontes seguras, tendo critérios de busca, onde buscá-la como buscar e usar o senso crítico (RESPONDENTE 29).

É o bibliotecário ter um senso crítico apurado e também fazer uma pesquisa em fonte confiável, procurando sempre fazer uma busca exaustiva, para chegar numa pesquisa segura e confiável (RESPONDENTE 30).

Cabe ressaltar que esse processo, além de abarcar o que foi exposto pelos discentes na questão, abrange também um preenchimento da necessidade informacional, resultando na ampliação do estado de conhecimento, em virtude de angariar novas aprendizagens ao seu bojo 
de atuação profissional, o que pode culminar em mais produção de segmentação científica.

Diante das respostas apresentadas, os estudantes apresentaram: ser leitores com grande potencial em contribuírem com a produção científica biblioteconômica, que ao finalizarem suas pesquisas científicas o resultado é bastante satisfatório, representando recuperação da informação eficiente, mas que necessitam conhecer com mais afinidade outro idioma para melhorarem na compreensão desses tipos de textos acadêmicos, correspondem ser bons conhecedores das TIC's e tem tendência de usarem com mais freqüência as fontes de informação eletrônica.

\section{Considerações Finais}

Com o crescimento incessantemente acelerado das TIC's, os estudantes do curso de Biblioteconomia são cada vez mais, beneficiados por uma variedade de ferramentas de trabalho ligadas ao cotidiano que engloba: estudos, estágios e outras atividades inerentes ao uso diário e que requer utilização de tecnologias para sua efetivação, a exemplo da Internet, ou mesmo de websites específicos na área das Ciências Sociais Aplicadas. A utilização das tecnologias também envolve bases de dados específicas e periódicos eletrônicos disponíveis para consultas e downloads de artigos,e outros documentos correlatos contribuindo para ampliação das possibilidades de leitura e, mais genericamente, no acesso à informação.

Nesta pesquisa, foi possível perceber como a busca da informação atrelada ao comportamento informacional, juntamente com a contribuição das TIC's, são fundamentais para a recuperação adequada de informação e de conteúdos disponíveis na Grande Rede Mundial de Computadores. Desta forma, não se pode ignorar esta realidade, muito menos recusar-se a aceitá-la como forma inovadora para a construção do conhecimento.

Acerca dos conhecimentos sobre as TIC's, os discentes demonstraram que estão bem atualizados, e devido estarmos no Século da Tecnologia e o uso desses aparatos tecnológicos são fundamentais em virtude da constante atualização profissional exigida pelo mercado de trabalho.

Diante dos sentimentos que são demonstrados após a realização de pesquisas científicas, foi possível verificar que: satisfação, confiança e otimismo são os mais acentuados, isso resulta na elaboração de investigações exitosas, o que demonstra que os discentes estão se sentindo saciados informacionalmente no que compete aos estudos realizados e seu resultado é a produção de conhecimento pode se tornar mais frequente, haja visto que essa disposição afetiva contribui para esse resultado.

A utilização de fontes de informação de outros idiomas devem ser incentivadas de maneira mais marcante por parte dos docentes para com 
seus acadêmicos, principalmente no estímulo a leituras técnico-científicas no idioma inglês, o mais confiável no escopo global, e o resultado demonstra a carência em empregá-lo com utilidade no dia a dia do acadêmico, haja vista o arcabouço que existe com abundância qualificatória nos periódicos científicos eletrônicos estrangeiros.

Pelos resultados apresentados no questionamento a respeito das fontes que são mais impactantes para suprir a lacuna de informação, demonstrou-se um total equilíbrio tanto no uso das fontes impressas quanto das digitais, no primeiro temos o aspecto da culturalidade milenar pelo apreço ao papel e na segunda, está a questão da facilidade e agilidade na obtenção desse tipo de fonte, também vale destacar que a grande maioria respondeu que usam os dois tipos com mais ênfase, abrigando tradicionalismo e tecnologia em presença do atual cenário em que estamos inseridos.

Percebe-se que a revista Ciência da Informação ainda é o periódico mais utilizado entre os discentes de Biblioteconomia da UFPA apesar da emergência de vários outros periódicos, contudo o fato deste periódico obter o conceito A2 justifica a sua soberania o que prova que os discentes são seletivos quanto às fontes a serem consultadas.

Os discentes de Biblioteconomia, retratados na população amostral deste trabalho, e até os usuários, de uma forma geral, necessitam ter acesso à informação, não somente em fontes institucionais tradicionais como as bibliotecas, mas, também, por meio da Internet. Todavia, a triagem na escolha dessas informações faz-se necessária diante do grande volume de conteúdos existentes que está à disposição dos usuários; e também devido haver um imenso material informacional considerado irrelevante do ponto de vista da qualidade da informação, inclusive daquela de natureza científica, o que o torna impróprio para uso efetivo para a Ciência.

Deste modo, os sistemas de recuperação da informação tradicionais passam por um processo de mudança constante, adquirindo novos formatos e roupagem, fazendo com que alunos de Biblioteconomia e demais usuários precisem se adaptar a eles continuamente. Esta mesma atitude deve ser seguida pelos profissionais da informação quanto à constante atualização no uso dessas TIC's, para um melhor desempenho profissional.

Por conseguinte, tanto estudantes de Biblioteconomia quanto bibliotecários precisam conhecer e saber utilizar os recursos informacionais tradicionais e os modernos, tendo em vista o melhor atendimento aos usuários nas unidades de informações em que atuam ou irão atuar.

O modelo de proceder durante o processo de recuperação das informações, principalmente na web, deve primar pelo máximo de tranquilidade, ensejando um sentimento de satisfação, assim, consequentemente, o insumo da atividade profissional do bibliotecário e do graduando de Biblioteconomia melhora consideravelmente, 
proporcionando mais qualidade à pesquisa acadêmica e a resolução de problemas ao atendimento a demandas informacionais.

Vale ressaltar que tanto a teoria de comportamento informacional proposto por Wilson quanto o ISP por Kuhlthau são válidos e podem ser aplicados em qualquer em qualquer área do conhecimento, haja visto apresentarem características de origem global. Sendo que a principal dificuldade encarado pelos graduandos durante todo o procedimento de busca da informação trata-se da questão do impedimento pessoal a respeito principalmente do conhecimento de outro idioma, o que reflete que os mesmos precisam investir com mais perseverança na sua formação acadêmica.

Destarte, conclui-se que o comportamento adotado no processo de busca da informação associado à colaboração das TIC's são componentes essenciais na formação do bibliotecário, sobretudo num contexto de produção e de reprodução de informações/textos em ambientes digitais, o que aponta para a construção de novos hábitos de leitura, fundamentadas no uso do computador.

Ao final deste trabalho, pode-se inferir que os objetivos foram alcançados, a o obtenção de respostas foi condizente com o tema estudado, e também causa instigação a prosseguir questionando.

\section{Referências}

BEAULIEU, Micheline. Approaches to user-based studies in information seeking and retrieval: a Sheffield perspective. Journal of Information Science, Shefield, v. 29, n. 4, p. 239-248, Aug. 2003. Disponível em: <http://jis.sagepub.com/content/29/4/239>. Acesso em: 2 out. 2011.

BRAGA, João Alberto de Oliveira. Aspectos relevantes para a seleção de metodologia adequada à pesquisa social em Ciência da Informação. In: MUELLER, Suzana Pinheiro Machado. Métodos para a pesquisa em Ciência da Informação. Brasília, DF: Thesaurus, 2007. p. 17-38.

CHOO, C. W. A Organização do conhecimento: como as organizações usam a informação para criar significado, construir conhecimento e tomar decisões. São Paulo: SENAC, 2003.

CRESPO, Isabel Merlo. Um estudo sobre o comportamento de busca e uso de informação de pesquisadores das áreas de biologia molecular e biotecnologia: impactos do Periódico científico eletrônico. 2005. 121 f. Dissertação (Mestrado em Comunicação) - Programa de Pós-Graduação em Comunicação e Informação, Faculdade de Biblioteconomia e Documentação, Universidade Federal do Rio Grande do Sul. Porto Alegre, 2005. Disponível em: <http://www.lume.ufrgs.br/bitstream/handle/10183/4387/000500810.pdf ?sequence $=1>$. Acesso em: 21 fev. 2012.

CRESPO, Isabel Melo; CAREGNATO, Sônia Elisa. Comportamento de Busca de Informação: uma comparação de dois modelos. Em questão: Revista 
da Faculdade de Biblioteconomia e Comunicação da UFRGS, Porto Alegre, v. 9, n. 2, p. 271-281, jul./ dez. 2003. Disponível em: < http://www.brapci.ufpr.br/download.php?dd0=9793> Acesso em: 24 set. 2011.

Padrões de comportamento de busca e uso de informação por pesquisadores de biologia molecular e biotecnologia. Ciência da Informação, Brasília, DF, v. 35, n. 3, p. 30-38, set./dez. 2006. Disponível em: < http://www.brapci.ufpr.br/download.php?dd0=2943>. Acesso em: 24 jan. 2012.

FIALHO, Janaína Ferreira. Ações, pensamentos, sentimentos e estratégias no processo de pesquisa acadêmica. Em questão: Revista da Faculdade de Biblioteconomia e Comunicação da UFRGS. Porto Alegre, v. 16, n. 2, p. 165-178, jul./dez. 2010. Disponível em: < http://www.brapci.ufpr.br/download.php?dd0=14244>. Acesso em: 25 set. 2011.

FIGUEIREDO, Nice Menezes. Textos avançados em referência e informação. São Paulo: Polis, 1996.

FURNIVAL, Ariadne Chloe Mary; ABE, Veridiana. Comportamento de busca na internet: um estudo exploratório em salas comunitárias. Encontros Bibli: Revista eletrônica de Biblioteconomia e Ciência da Informação, Florianópolis, v. 13, n. 25, p. 153-173, jan./jun., 2008. Disponível em: < http://www.periodicos.ufsc.br/index.php/eb/article/view/1518-

2924.2008v13n25p156/887>. Acesso em: 15 ago. 2011.

GIL, Antonio Carlos. Como elaborar projetos de pesquisa. 4. ed. São Paulo: Atlas, 2009.

IMMIG, Cássio Felipe. Informação para prática docente: o comportamento informacional dos professores de ensino fundamental da Escola Municipal Selvino Ritter do município de Estância Velha - RS. 2007. 69 f. Trabalho de Conclusão de Curso (Graduação) - Faculdade de Biblioteconomia e Comunicação, Departamento de Ciência da Informação, Universidade Federal do Rio Grande do Sul, Porto Alegre, 2007. Disponível em: < http://www.geocities.ws/cassioimmig/TCC/tcc.pdf>. Acesso em: $21 \mathrm{fev}$. 2012.

KUHLTHAU, Carol Collier. Inside the search process: information seeking from the user's perspective. Journal of the American Society for Information Science, New Jersey, v. 42, n. 5, p. 361-371, June, 1991. Disponível em: < http://bogliolo.eci.ufmg.br/downloads/kuhlthau.pdf>. Acesso em: 1 out. 2011.

Disponível

Information Search Process. New Jersey, 2004. 20 slides: color. http://comminfo.rutgers.edu/ kuhlthau/information_search_process.htm >. Acesso em: 2 out. 2012. 
. The Role of Experience in the Information Search Process of an Early Career Information Worker: Perceptions of Uncertainty, Complexity, Construction, and Sources. Journal of the American Society for Information Science. New Jersey, v. 50, n. 5, p. 399-412. 1999. Disponível em: http://comminfo.rutgers.edu/ tefko/Courses/612/Articles/KuhlthauExperi ence.pdf>. Acesso em: 2 out. 2011.

. Kuhlthau's information search process. In: FISHER, R.; ERDELEZ, S.; MCKECHNIE, L. E. F. (Ed.). Theories of information behavior. Medford: Information today, $2005 . \quad$ Disponível em: $<$ http://www.scils.reutgers.edu/kuhlthau/news/isp_chapter.htm>. Acesso em: 5 nov. 2011.

KULHTHAU, Carol Collier.; TAMA, S. L. Information search process of lawyers: a call for just for me 'information services'. Journal of Documentation, New Jersey, v. 57, n. 1, p. 25-43, Jan., 2001. Disponível em:

http://comminfo.rutgers.edu/ tefko/Courses/612/Articles/KuhlthauTama. pdf >. Acesso em: 13 out. 2011.

LAKATOS, Eva Maria; MARCONI, Marina de Andrade. Fundamentos da metodologia cientifica. 6. ed. São Paulo: Atlas, 2005.

Técnicas de pesquisa: planejamento e execução de pesquisas, amostragens e técnicas de pesquisa, elaboração, análise e interpretação de dados. 7. ed. São Paulo: Atlas, 2009.

MARTINEZ-SILVEIRA, Martha; ODDONE, Nanci. Necessidades e comportamento informacional: conceitos e modelos. Ciência da Informação, Brasília, DF, v. 36, n. 1, p. 118-127, maio/ago. 2007. Disponível em:

http://revista.ibict.br/index.php/ciinf/article/view/797/725>. Acesso em: 20 dez. 2011.

MEADOWS. Arthur Jack. A Comunicação cientifica. Tradução Antônio Agenor Briquet de Lemos. Brasília, DF: Briquet de Lemos, 1999. Tradução de: Comunicating research.

OLIVEIRA, S. L. de. Tratado de Metodologia Científica: Projetos de Pesquisas, TGI, TCC, Monografias, Dissertações e Teses. São Paulo: Pioneira, 2001.

ORTOLL-ESPINET, Eva; GONZÁLEZ-TERUEL, Aurora; GILABERT-ROS, Esther. Information Behaviour of University Students. In: QUALITATIVE AND QUANTITATIVE METHODS IN LIBRARIES, INTERNATIONAL CONFERENCE. 25., 2009, Crete. Proceedings... Crete, 2009. Disponível em: <http://eproceedings.worldscinet.com/9789814299701/9789814299701_ 0020.html>. Acesso em: 9 out. 2011. 
SILVA, Patrícia Maria. O Comportamento dos usuários de bibliotecas em sistemas de informação. Transinformação, Campinas, SP, v. 20, n. 3, p. 255-263, set./dez. 2008. Disponível em: < http://www.brapci.ufpr.br/download.php?dd0=5605>. Acesso em: 24 set. 2011.

SILVA, Edna Lúcia da; MENEZES, Estera Muszkat. Metodologia da pesquisa e elaboração de dissertação. 3. ed. rev. e atual. Florianópolis: Laboratório de Ensino a Distância da UFSC, 2001. Também disponível em: $<$

http://projetos.inf.ufsc.br/arquivos/Metodologia\%20da\%20Pesquisa $\% 203$ a\%20edicao.pdf>. Acesso em: 9 fev. 2012.

SOUTO, Leonardo Fernandes Souto. Informação seletiva, mediação e tecnologia: a evolução dos serviços de disseminação seletiva da informação. Rio de Janeiro: Interciência, 2010.

UNIVERSIDADE FEDERAL DO PARÁ. Instituto de Ciências Sociais Aplicadas. Biblioteconomia: alunos matriculados. Belém, 2011. Disponível em:

http://www.icsa.ufpa.br/index.php?option=com_content\&view=article\&id =38\&Itemid=182>. Acesso em: 29 dez. 2011.

VENÂNCIO, Ludmila Salomão; NASSIF, Mônica Erichsen. O Comportamento de busca de informação sob o enfoque da cognição situada: um estudo empírico qualitativo. Ciência da Informação, Brasília, DF, v. 37, n. 1, p. 95-106, jan./abr. 2008. Disponível em: <http://www.brapci.ufpr.br/download.php?dd0=8542>. Acesso em: 25 set. 2011.

WILSON, T. D. Models in Information Behaviour Research. Journal of Documentation, London, v. 55, n. 3, p. 249-271, June, 1999. Disponível em: < http://informationr.net/tdw/publ/papers/1999JDoc.html>. Acesso em: 15 out. 2011.

. Human information behavior. Informing science. Sheffield, v. 3, n. 2, p. 49-53, 2000. Disponível em: < http://inform.nu/Articles/Vol3/v3n2p49-56.pdf>. Acesso em: 7 jan. 2012.

Documentation,

London, v. 62 n. 6, p. 658-670, Dec. 2006. Disponível em: $<$ http://informationr.net/tdw/publ/papers/1981infoneeds.pdf $>$. Acesso em: 7 jan. 2011.

Information behaviour: an interdisciplinary perspective. Information Proceeding and Management, Georgia, v. 33, n. 4, p. 551572, $1997 . \quad$ Disponível em: <http://ptarpp2.uitm.edu.my/ptarpprack/silibus/is772/infoBehavior.pdf > . Acesso em: 7 jan. 2012. 
O comportamento no processo de busca da informação por

Biblioteconomia no Estado do Pará

YIN, R. K. Estudo de caso: planejamento e métodos. 2. ed. Porto Alegre: Bookman,

2001. 